\title{
Tolerably mobile subsea foundations - observations of performance
}

\author{
M. L. COCJIN*, S. M. GOURVENEC*, D. J. WHITE* and M. F. RANDOLPH*
}

\begin{abstract}
Increasing demands for oil and gas exploration in deep water with soft seabed conditions are resulting in the size and weight of subsea shallow foundations stretching the capabilities of installation technologies. One innovation to reduce foundation footprints involves designing foundations to move in a tolerable manner to absorb applied loads rather than being engineered to resist these loads and remain stationary. Critical design considerations are the evolution of foundation capacity and the mode of foundation displacement. The foundation should be designed to slide with acceptable settlement and rotation to prevent overstressing the joints with connected pipelines. This paper presents observations from centrifuge model tests of a mat foundation designed to slide under applied loading. The foundation is subjected to a simulated lifetime of operation, with many cycles of sliding and intervening periods of consolidation. The results provide insights to assist design, including a remarkable rise in the lateral foundation resistance over the sliding events, through repeated episodes of shearing and reconsolidation, and quantification of the accumulated settlements and rotations. The foundation is shown to translate with minimal rotation. The settlement between sliding events is more significant. This is due to the tendency for soft clay to contract on shearing, as excess pore pressures generated during sliding subsequently dissipate. The sliding-induced consolidation settlements control the tolerability of the performance of the mobile foundation.
\end{abstract}

KEYWORDS: bearing capacity; consolidation; settlement

\section{BACKGROUND}

Offshore oil and gas developments are increasingly adopting subsea architecture, with multiple wells connected by a network of in-field flowlines and associated pipeline infrastructure such as manifolds, end terminations and in-line structures. Pipeline infrastructure is typically supported on shallow foundations or 'mudmats' that range from $3 \mathrm{~m}$ to over $30 \mathrm{~m}$ in edge length (Fig. 1).

Subsea pipelines experience periodic cycles of thermal expansion and contraction due to start-up and shutdown operations over the life cycle of a field. The thermal expansion of a pipeline causes horizontal loads, moments and in some cases torsion to be transferred to the mudmats supporting the pipeline infrastructure.

Conventionally, mudmats are designed to resist these operational loads and remain stationary. The size of mudmats is increasing to suit heavier subsea infrastructure and to spread load across sufficient area on very soft soils found in deeper water. Mudmats are ideally installed by the same vessel that lays the pipeline, which imposes limitations on the size and weight of mudmats that can be handled, while a second vessel on site for installation of the mudmats may be financially prohibitive. This impasse provides the motivation to optimise design solutions. Various approaches have been proposed for reducing subsea mudmat size and weight, including optimisation of mudmat configuration through the provision of corner pin piles and internal shear keys (Gaudin et al., 2012; Mana et al., 2012; Dimmock et al., 2013; Feng et al., 2014a), reducing conservatism in design methodology (Feng et al., 2014b), and reliance on enhanced shear strength

Manuscript received 3 June 2014; revised manuscript accepted 17 September 2014. Published online ahead of print 21 November 2014. Discussion on this paper closes on 1 April 2015, for further details see p. ii.

$*$ Centre for Offshore Foundation Systems - M053, node of ARC Centre for Geotechnical Science and Engineering, University of Western Australia, Crawley, Perth, WA, Australia.

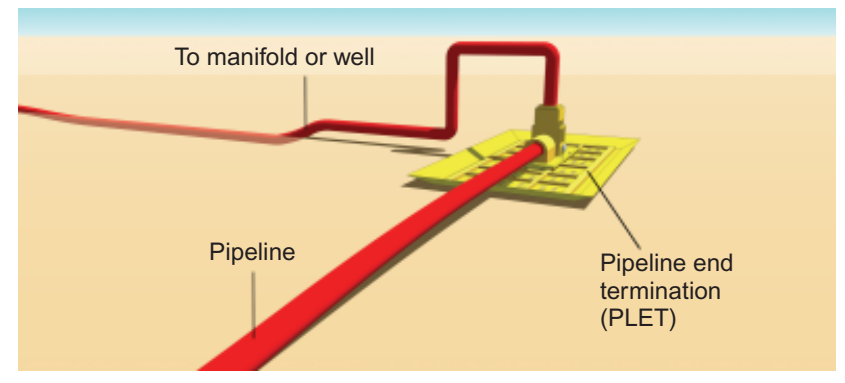

Fig. 1. Typical layout of pipeline connections with associated infrastructure

due to consolidation between set down and operation (Gourvenec et al., 2014).

The study presented in this paper addresses the potential of tolerable foundation mobility to reduce foundation footprints - that is, foundations that are designed to move within acceptable serviceability limits to relieve some of the applied loads, rather than being engineered sufficiently large to resist all loading. Foundation mobility is a radical, but a logical progression of the now widely accepted practice of allowing deep-water submarine pipelines to move axially and buckle laterally in response to thermal expansion as an alternative to providing expensive restraints against movement. A contrast exists between onshore and offshore practice in terms of tolerable mobility. In typical onshore applications, the ultimate limit load is reached at displacements much larger than those considered serviceably tolerable. In the subsea mudmat case, tolerable displacements exceed by far the displacement needed to mobilise the limiting resistance (although the tolerable rotations may still be small and comparable to onshore cases).

The design challenge is to engineer a foundation that can undergo controlled and limited sliding across the seabed to relieve some of the applied operational (pipeline) loads, but at the same time does not damage pipeline connection points 
through unwanted rotation or excessive settlement. The notion of foundation mobility has been proposed in the past (Cathie et al., 2008) and methods to address some aspects of geotechnical design have been suggested (Bretelle \& Wallerand, 2013; Deeks et al., 2014). However, no data on the performance of mobile foundations are available in the public domain on which to base or assess the proposed methods.

This paper presents results from centrifuge model tests of a mudmat foundation on soft clay. The foundation was set down under an operative vertical load and subjected to periodic undrained translation, unconstrained against rotation about either the long or short axis, with intervening periods of consolidation. Conditions representative of the field were modelled. The translation of the foundation with intervening periods of rest represented the response to thermal expansion and contraction of a connected pipeline during cycles of start-up and shutdown operations.

Changes in sliding resistance, settlements and rotation of the foundation during sliding cycles and intervening periods of rests are presented. Observed changes in topography and strength of underlying soil exposed to periodic remoulding due to foundation sliding and intervening periods of reconsolidation are also presented.

\section{EXPERIMENTAL PROGRAMME}

Geotechnical centrifuge facility and equipment

The tests were conducted at the University of Western Australia - Centre for Offshore Foundation Systems (UWACOFS) fixed beam centrifuge, which has a nominal radius of $1.8 \mathrm{~m}$ (Randolph et al., 1991). The tests reported in this paper were carried out at an acceleration level of $100 \mathrm{~g}$. The soil sample was set up in a rectangular strong box with internal dimensions $390 \mathrm{~mm}$ by $650 \mathrm{~mm}$ by $300 \mathrm{~mm}$ high. A loading actuator with vertical and horizontal axes of motion (De Catania et al., 2010) was employed. Data acquisition used a high-speed Ethernet-based system with data streaming in real time to a remote desktop (Gaudin et al., 2009).

\section{Mudmat foundation model}

A rectangular mudmat foundation with breadth to length aspect ratio $B / L=0 \cdot 5$ was used in this study. The model mudmat foundation, as illustrated in Fig. 2, designed to act as a rigid slab, was fabricated with underside base plate dimensions $B=50 \mathrm{~mm}$ and $L=100 \mathrm{~mm}(5 \mathrm{~m}$ by $10 \mathrm{~m}$ prototype scale), and height $5 \mathrm{~mm}(0.5 \mathrm{~m}$ prototype scale). An edge 'ski' was inclined at $30^{\circ}$ giving plan dimensions of $67.3 \mathrm{~mm}$ by $117.3 \mathrm{~mm}(6.7 \mathrm{~m}$ by $11.7 \mathrm{~m}$ prototype scale) at the top surface (Fig. 2). The purpose of the 'ski' is to reduce foundation tipping (overturning) and encourage sliding.

The rectangular mat was fabricated from acetal (polyoxymethylene (POM)) with density of $1410 \mathrm{~kg} / \mathrm{m}^{3}$. The low density allows the self-weight bearing pressure of the model foundation to match load levels of mudmats employed in the field (which in practice are made of heavier material but are not solid in cross-section). The Young's modulus and Poisson ratio of acetal are $E_{\text {acetal }}=3 \cdot 1 \mathrm{GPa}$, and $v_{\text {acetal }}=0 \cdot 39$, respectively; sufficiently stiff to be considered as rigid relative to the considerably less stiff soil.

Fine silica sand was glued to the base plate to provide a rough foundation-soil interface, whereas faces of the edge 'ski' had a smooth finish. A rough condition represents an extreme interface condition, with a smoother interface leading to reduced shear stresses and shear-induced excess pore pressure in the underlying soil. However, the same trends and principles of behaviour described here would still be applicable. Many types of seabed material would lead to scouring, and gradual roughening, of any coating applied to the underside of the mudmat.

The midpoint of the underside base plate was taken as the reference point (RP) where the loads and displacements are defined. The positive sign convention for the loads and displacements is illustrated in Fig. 2(c), following Butterfield et al. (1997).

\section{Loading arm}

The model mudmat foundation was attached to a specially designed loading arm that enabled free rotation of the foundation about two axes and control of vertical load, as shown in Fig. 3. The arm was connected to the foundation through a hinged joint $10 \mathrm{~mm}$ above the top of the base plate (Fig. 2(a)). The hinge enables rotation about the short axis of the foundation, while a roller bearing within the

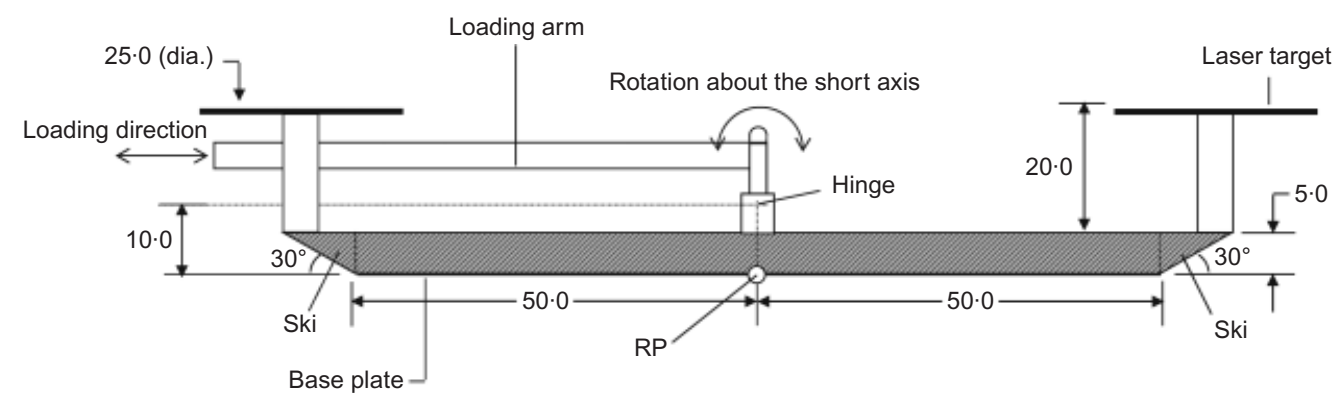

(a)
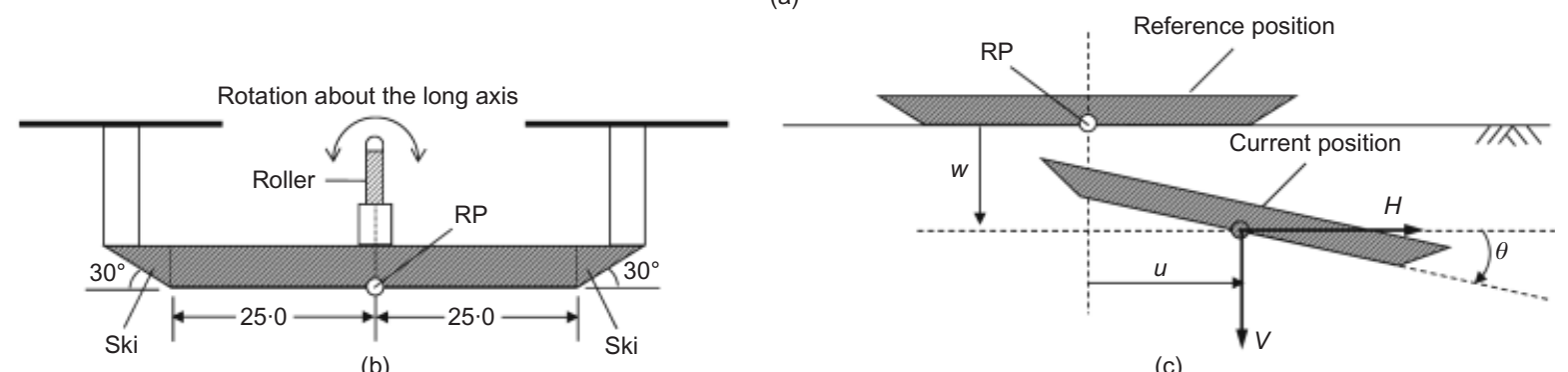

(b)

(c)

Fig. 2. Model foundation: (a) long side; (b) short side; (c) positive sense for loads and displacements (after Butterfield et al., 1997) (units: millimetres in model scale) 


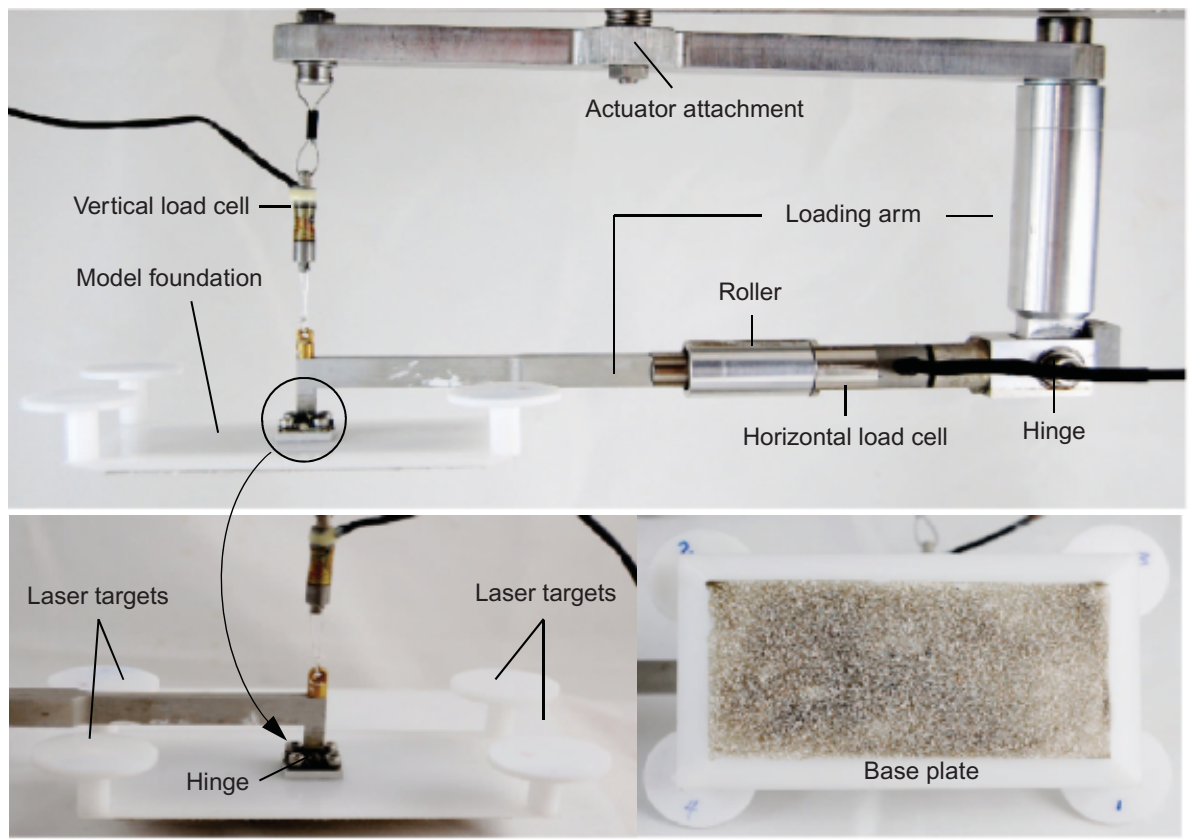

Fig. 3. Test set-up on loading arm

loading arm (Fig. 3) enables rotation about the long axis (Fig. 2(b)).

A vertically oriented load cell was connected directly above the RP through a padeye to measure the operative vertical foundation-seabed load (relative to the equilibrium state under the self-weight of the foundation and loading arm), while an S-shaped axial load cell was positioned inline with the loading arm between the roller bearing and the hinge at the end of the loading arm to measure the applied horizontal load (Fig. 3).

\section{Instrumentation}

Vertical displacement at the four corners of the acetal mudmat foundation were measured by four Keyence ${ }^{\circledR}$ laser displacement sensors (model LB-70-11) mounted on a steel plate fixed to the actuator. The sensors track the circular disc targets installed at each corner of the foundation (Figs 2 and 3 ), giving vertical displacements at these locations. The average of the four laser measurements was taken to provide the vertical displacement of the mudmat foundation. Rotation about the RP (at centre of base of mudmat) was determined from the difference between pairs of vertical laser readings, while the horizontal travel of the model foundation was measured using the horizontal displacement transducer of the actuator.

\section{Soil sample}

Kaolin slurry with water content twice the liquid limit $(120 \%)$ was normally consolidated in the centrifuge at $100 \mathrm{~g}$ for 3.5 days. Geotechnical properties of kaolin clay as determined from laboratory element tests are given in Table 1 (Stewart, 1992; Acosta-Martinez \& Gourvenec, 2006).

Two-way drainage for consolidation was provided by means of a $50 \mathrm{~mm}$ thick silica sand layer at the bottom of the strongbox. After consolidation was essentially complete, a thin layer of soil $(\sim 0-5 \mathrm{~mm}$ or $0-0.5 \mathrm{~m}$ prototype scale, depending on the location in the box) was scraped from the top of the sample to provide a smooth and level surface. After re-equilibration and swelling, the final height of the soil sample was $130 \mathrm{~mm}$, equivalent to $13 \mathrm{~m}$ depth at $100 \mathrm{~g}$.
Table 1. Characteristics of Kaolin clay (after Stewart (1992) and Acosta-Martinez \& Gourvenec (2006))

\begin{tabular}{l|c}
\hline Property & Value \\
\hline Liquid limit, LL: $\%$ & $61 \%$ \\
Plastic limit, PL: $\%$ & $27 \%$ \\
Soil particle density, $G_{\mathrm{S}}$ & $2 \cdot 6$ \\
Plasticity index, $I_{\mathrm{p}}$ & 34 \\
Critical state friction constant, $M$ & $0 \cdot 92$ \\
Void ratio at $p^{\prime}=1 \mathrm{kPa}$ on critical state line (CSL), $e_{\mathrm{cs}}$ & $2 \cdot 14$ \\
Slope of normal consolidation line, $\lambda$ & $0 \cdot 205$ \\
Slope of swelling line, $\kappa$ & $0 \cdot 044$ \\
Poisson ratio, $v$ & $0 \cdot 3$ \\
Angle of internal friction, $\phi^{\prime}=\sin ^{-1}[3 M /(6+M)]$ : degrees & $23 \cdot 5$ \\
\hline
\end{tabular}

\section{Site characterisation}

Intact and remoulded shear strength profiles and consolidation characteristics of the soil sample were determined using miniature in-situ characterisation tools. The in-situ effective vertical stress profile was determined from the profile of saturated unit weight, which was obtained from moisture content measurements following the testing programme.

Undrained shear strength characteristics. T-bar tests (Stewart \& Randolph, 1991, 1994) were conducted on the soil sample to determine the undrained shear strength, $s_{\mathrm{u}}$. A standard miniature T-bar with a projected penetrating area of $100 \mathrm{~mm}^{2}$ was used. The tests were carried out at a penetration rate of $1 \mathrm{~mm} / \mathrm{s}$ to ensure undrained conditions (Randolph \& Hope, 2004).

Figure 4(a) plots the T-bar resistance, $q_{\mathrm{T}-\text { bar }}$ with depth, $z$ where $s_{\mathrm{u}}=q_{\mathrm{T}-\text { bar }} / N_{\text {T-bar }}$ was interpreted assuming a constant T-bar factor of $10 \cdot 5$ (Stewart \& Randolph, 1994). The insitu, intact shear strength of the soil was taken from the first penetration resistance (marked by a thicker line in Fig. 4(a)), and was approximated to vary linearly with depth as

$$
s_{\mathrm{u}}=s_{\mathrm{um}}+k z
$$



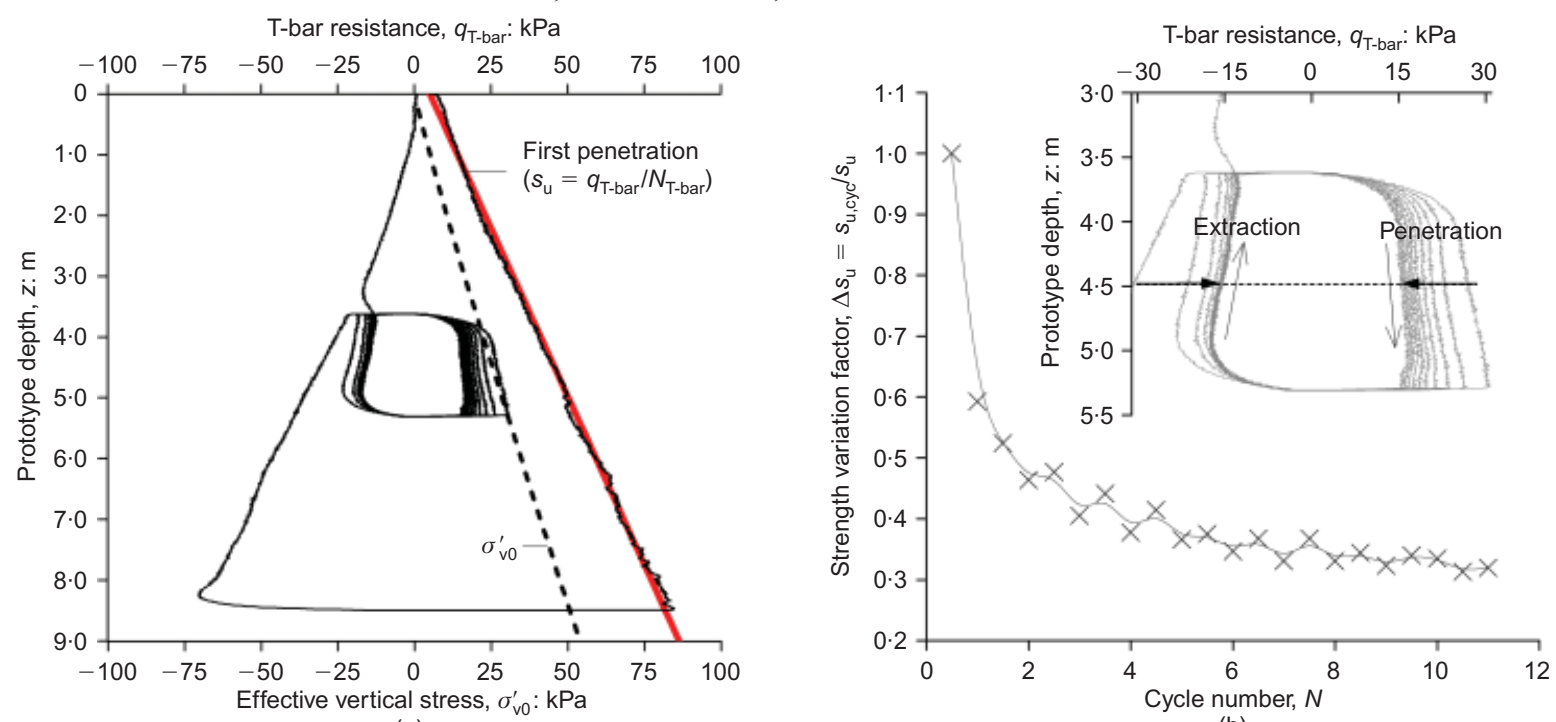

(a)

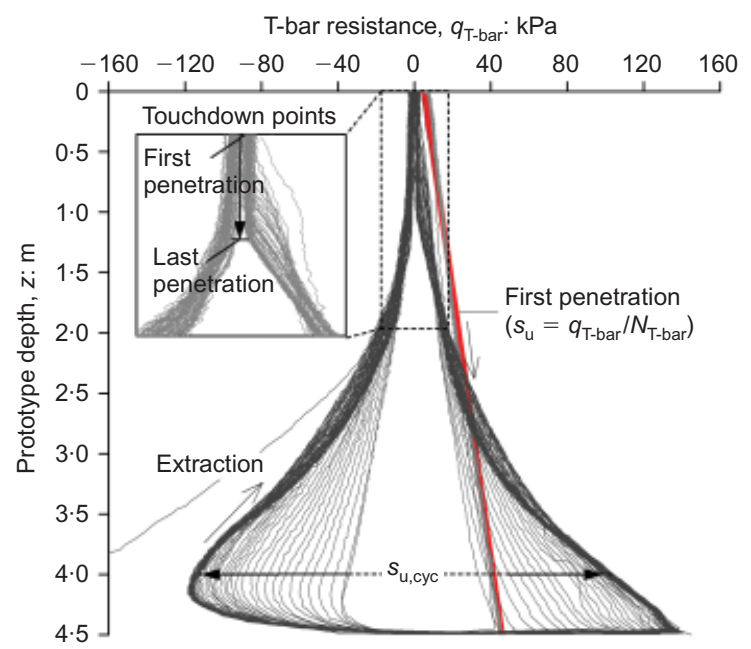

(c)

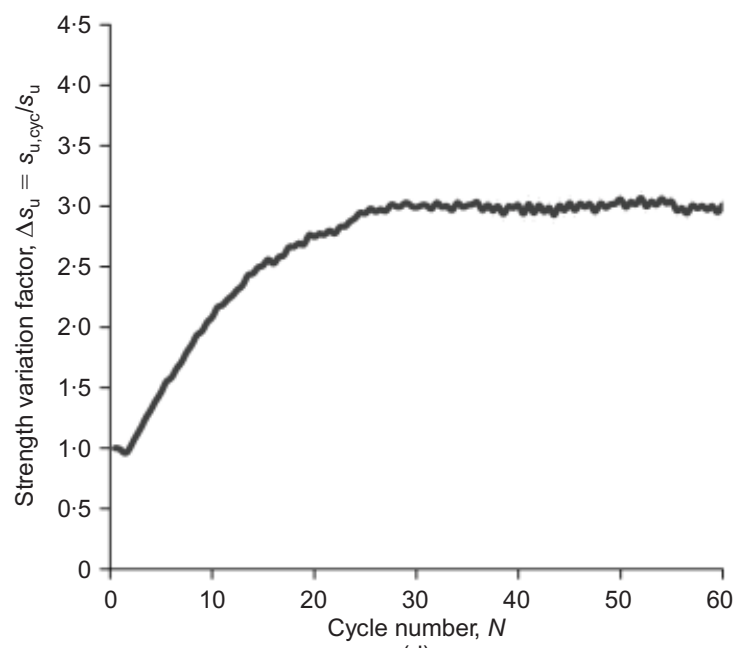

(d)

Fig. 4. (a) T-bar resistance, $q_{\mathrm{T}-\mathrm{bar}}$, for T-bar 1 test and effective vertical stress, $\sigma_{\mathrm{v} 0}^{\prime}$, profiles with prototype depth, $z$; (b) strength variation factor, $\Delta s_{\mathrm{u}}=s_{\mathrm{u}, \mathrm{cyc}} / s_{\mathrm{u}}$, against cycle number for T-bar 1 test, showing load-displacement path of cyclic loading (inset); (c) T-bar resistance, $q_{\text {T-bar, }}$, profile with prototype depth, $z$, for T-bar 2 test; (d) strength variation factor, $\Delta s_{u}$, against cycle number for T-bar 2 test

where $s_{\mathrm{um}}=0.53 \mathrm{kPa}$ is the mudline shear strength and $k=0.86 \mathrm{kPa} / \mathrm{m}$ is the gradient of strength with depth. The T-bar extraction was halted at a depth of $40 \mathrm{~mm}$ below the mudline and ten cycles of penetration and extraction were carried out over the model depth range of $40-60 \mathrm{~mm}$ before the full extraction of the T-bar (Fig. 4(b)). The cyclic sequence to achieve fully remoulded conditions is used to define an accurate zero reference for the resistance data, and to measure the remoulded strength of the soil sample. The strength variation factor, $\Delta s_{\mathrm{u}}=s_{\mathrm{u}, \mathrm{cyc}} / s_{\mathrm{u}}$ indicates the change in strength during T-bar cycles, where $s_{\mathrm{u}, \mathrm{cyc}}$ is the strength measured during cycles of penetration and extraction, and is plotted against cycle number in Fig. 4(b). The reduction in strength during cyclic penetration and extraction observed in Fig. 4(b) is conventionally described as a remoulding process (e.g. Randolph, 2004), and is predominantly due to the generation of positive excess pore pressure, but may also reflect a change in the mobilised strength ratio or a degradation of the soil structure (as discussed by Randolph et al., 2007; White \& Hodder, 2010; Hodder et al., 2013). After a few passes, a steady and reduced T-bar resistance is mobi- lised, indicative of the remoulded strength of the soil. The final value of $\Delta s_{\mathrm{u}} \sim 0.4$ indicates a sensitivity, $S_{\mathrm{t}} \sim 2.4$ where $S_{\mathrm{t}}$ is defined as the ratio of the intact to remoulded strength as measured by way of cyclic penetrometer tests (Randolph, 2004; White \& Hodder, 2010).

A second T-bar test involved cycles of penetration and full extraction with a rest period of $780 \mathrm{~s}$ (representing 0.25 years in prototype scale), with the T-bar held above the mudline for the periods of rest. In total, 60 cycles were conducted. The measured profiles of $q_{\text {T-bar }}$ with depth, $z$, are presented in Fig. 4(c). This test was designed to investigate the regain in soil strength during 0.25 years of reconsolidation following undrained failure (with an associated generation of excess pore pressure). The strength variation factor, $\Delta s_{\mathrm{u}}$, inferred at penetration depth of $4.0 \mathrm{~m}$ is presented in Fig. 4(d) and indicates an increase in undrained shear strength with increasing loading cycles, to a final strength of $\sim 3.0$ times the in-situ value. This ratio is similar to the relative penetration resistance during the first penetration of T-bar tests performed at drained and undrained rates in kaolin (House et al., 2001). 
This contrasting behaviour between the two T-bar tests indicates that the gain in strength from reconsolidation can eclipse the loss of strength caused by remoulding. This behaviour is consistent with a critical state framework, in which undrained failure of contractile material around the Tbar generates positive pore pressure, which dissipates during the reconsolidation period causing a reduction in moisture content and a gain in undrained strength (see White \& Hodder, 2010). The reduction in moisture content is evident in the local settlement of the soil surface, which causes the touchdown point when T-bar resistance is first recorded to become deeper with each cycle (Fig. 4(c)). The mechanism of soil strength regain due to remoulding and reconsolidation is shown later to be relevant to the sliding foundation response.

Moisture content determination. Figure 4(a) shows the profile of in-situ effective vertical stress, $\sigma_{\mathrm{v} 0}^{\prime}$ with depth as derived from moisture content data obtained from core soil samples taken at different locations in the box. The average effective unit weight over the depth of the sample $(\sim 2 B)$ is $\gamma^{\prime}=5.7 \mathrm{kN} / \mathrm{m}^{3}$, leading to a ratio of T-bar undrained shear strength to in-situ effective vertical stress of $s_{\mathrm{u}} / \sigma_{\mathrm{v} 0}^{\prime} \sim 0.15$ over the depth investigated.

Consolidation characteristics. The operative coefficient of consolidation that governs the consolidation processes during the mudmat foundation tests was determined as follows.

First, determination of the horizontal coefficient of consolidation, $c_{\mathrm{h}}$ : the horizontal coefficient of consolidation, $c_{\mathrm{h}}$ of the soil sample was determined through a series of inflight miniature piezocone penetrometer (CPTu) dissipation tests, where the pore water flow is primarily radial, but also different zones of soil experience plastic or unloading effective stress paths, at model depths below the mudline, $z_{\mathrm{CPTu}}=40,70$ and $90 \mathrm{~mm}$ (correspondingly $z_{\mathrm{CPTu}} / B=0 \cdot 8$, 1.4 and $1 \cdot 8$ ). Results from these tests are presented in Fig. 5(a) where change in excess pore pressure as a ratio of the initial excess pore pressure, $\Delta u_{\mathrm{e}} / \Delta u_{\mathrm{e}, \mathrm{i}}$ is plotted against a time factor, $T^{*}$ given by

$$
T^{*}=\frac{c_{\mathrm{h}} t}{R^{2} I_{\mathrm{r}}^{0 \cdot 5}}
$$

with $R$ being the piezocone radius $=5 \mathrm{~mm}$. Dissipation curves presented in Fig. 5(a) correspond to a rigidity index, $I_{\mathrm{r}}$ of 88 following the method proposed by Mayne (2001), and after a correction made for the initial value of excess pore pressure as suggested by Sully et al. (1999).

Values of the horizontal coefficient of consolidation, $c_{\mathrm{h}}$, were extrapolated from these dissipation curves using a correlation with a theoretical solution based on $T_{50}$, the time for dissipation of $50 \%$ of the initial excess pore pressure (Teh \& Houlsby, 1991). Values range from $7.7<c_{\mathrm{h}}\left(\mathrm{m}^{2} /\right.$ year $)<13.0$, and are plotted in Fig. 5(b) against effective vertical stress, $\sigma_{\mathrm{v}}^{\prime}$ as given in Fig. 4(a) corresponding to the level of $z_{\mathrm{CPTu}}$. The plot also includes recent results obtained by Chow et al. (2014) and Colreavy's unpublished data (2013) from in-flight piezocone tests on UWA kaolin clay with $c_{\mathrm{h}}$ values at higher levels of $\sigma_{\mathrm{v}}^{\prime}$.

Second, determination of vertical coefficient of consolidation, $c_{\mathrm{v}}$ : a variation of the vertical coefficient of consolidation, $c_{\mathrm{V}}$ with effective vertical stress, $\sigma_{\mathrm{v}}^{\prime}$ for $\sigma_{\mathrm{v}}^{\prime}<500 \mathrm{kPa}$ is obtained from one-dimensional Rowe cell consolidation tests on UWA kaolin clay reported in House et al. (2001), and can be expressed as

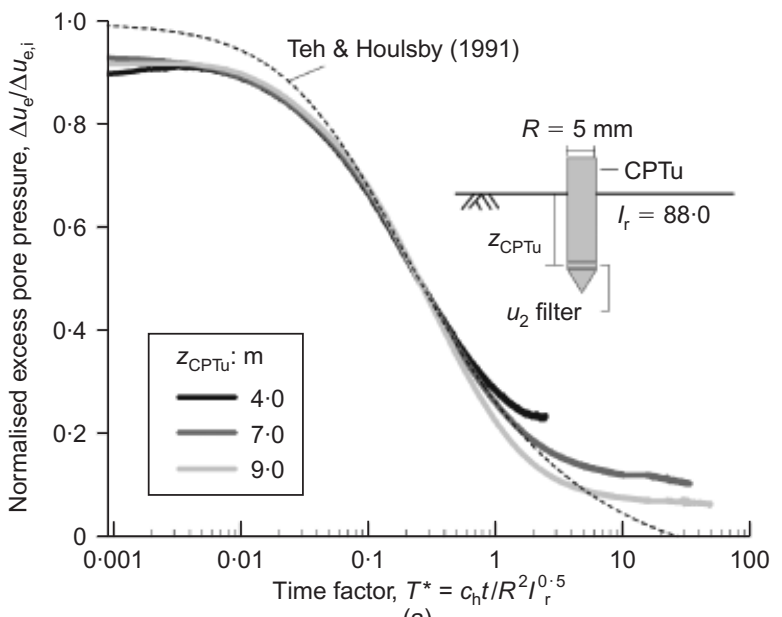

(a)

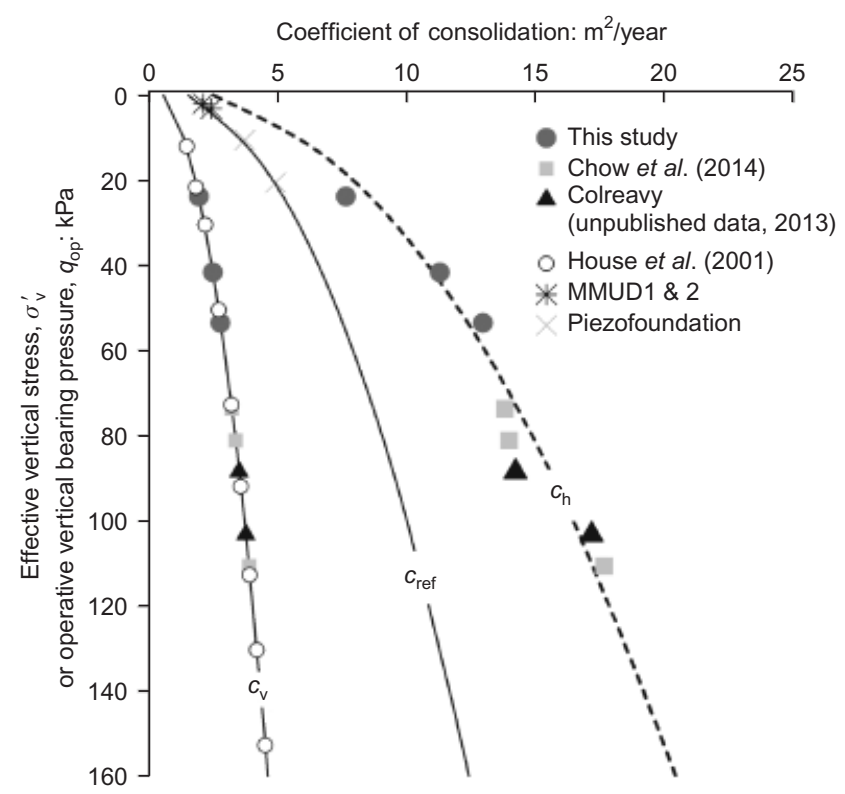

Fig. 5. Piezocone tests results showing: (a) dissipation of excess pore pressure at the level of filter $u_{2}$ expressed as a ratio of excess pore pressure over initial value, $\Delta u_{\mathrm{e}} / \Delta u_{\mathrm{e}, \mathrm{i}}$, plotted against time factor, $T^{*}=c_{\mathrm{h}} t / R^{2} I_{\mathrm{r}}{ }^{0.5}$; (b) coefficient of consolidation plotted against effective vertical stress, $\sigma_{\mathrm{v}}^{\prime}$

$$
c_{\mathrm{V}}=\left(0 \cdot 3+0 \cdot 16 \sigma_{\mathrm{v}}^{\prime}\right)^{0 \cdot 47}
$$

with $c_{\mathrm{v}}$ and $\sigma_{\mathrm{v}}^{\prime}$ being in $\mathrm{m}^{2} /$ year and $\mathrm{kPa}$, respectively. From this expression, the average ratio of the horizontal to vertical coefficient of consolidation, $c_{\mathrm{h}} / c_{\mathrm{V}}$ for the range of stress level relevant to the tests (i.e. $\sigma_{\mathrm{v}}^{\prime}<120 \mathrm{kPa}$ ) was obtained as $4 \cdot 4$. This is consistent with, although slightly greater than, the ratio of 3.5 for normally consolidated kaolin argued theoretically by Mahmoodzadeh et al. (2014).

Third, determination of representative coefficient of consolidation for foundation response, $c_{\text {ref: }}$ to provide additional information on the rate of consolidation beneath the model mudmat foundation, a series of load-controlled dissipation tests using a 'piezofoundation' was carried out. These tests are akin to a plate loading test, but with pore pressure measurement. A rigid, circular foundation (diameter $=$ $40 \mathrm{~mm}$ model scale) instrumented with a pore pressure sensor at the centre of its base plate, and a load cell to measure an operative vertical bearing pressure, $q_{\text {op }}$ (which is held constant during a dissipation phase) was used. During the tests, the piezofoundation was placed on the soil surface and loaded to the desired $q_{\text {op }}$ of $10.5 \mathrm{kPa}(\mathrm{PF} 1)$ and $20 \cdot 5 \mathrm{kPa}(\mathrm{PF} 2)$ 
Results from these tests are presented in Fig. 6 showing the change in excess pore pressure as a ratio of the initial excess pore pressure, $\Delta u_{\mathrm{e}} / \Delta u_{\mathrm{e}, \mathrm{i}}$ against a time factor, $T$ given by

$$
T=\frac{c_{\text {ref }} t}{D^{2}}
$$

where $t$ is dissipation time and $D$ is foundation diameter. $c_{\text {ref }}$ is an operative coefficient of consolidation representative of the rate of consolidation underneath a foundation carrying a steady vertical bearing pressure of $q_{\text {op }}$ with $c_{\text {ref }}$ being $c_{\mathrm{V}}<c_{\text {ref }}<c_{\mathrm{h}}$.

Values of $c_{\text {ref }}$ were determined by fitting the measured dissipation curves to solutions based on elastic isotropic finite-element analysis of a rough, circular foundation (Gourvenec \& Randolph, 2010) and on elasto-plastic finiteelement analysis of a rectangular foundation with $B / L=0.5$ (Feng \& Gourvenec (unpublished data, 2014)). A value of $c_{\text {ref }}=2 \cdot 7 c_{\mathrm{V}}$ was obtained, with $c_{\mathrm{V}}$ given by equation (3) assuming $\sigma_{\mathrm{v}}^{\prime}=q_{\mathrm{op}}$. Values of $c_{\text {ref }}$ projected for the range of bearing pressures relevant to the study are shown in Fig. 5(b).

The excess pore pressure time histories observed with the piezofoundation and captured by the finite-element analysis (Gourvenec \& Randolph, 2010; Feng \& Gourvenec, (unpublished data, 2014)) exhibit the characteristic Mandel-Cryer effect (Mandel, 1950; Cryer, 1963), with excess pore pressure increasing above the initial value of stress change during the early stage of consolidation. The Mandel-Cryer effect is a stress transfer effect significant in three-dimensional consolidation. It results from the more rapid dissipation of excess pore pressure in soil near the edges of the foundation than near the centre. The resulting (greater) compression of the soil at the edges leads to a temporary (initial) transfer of total stress, and hence increase in excess pore pressure, in the central part of the foundation.

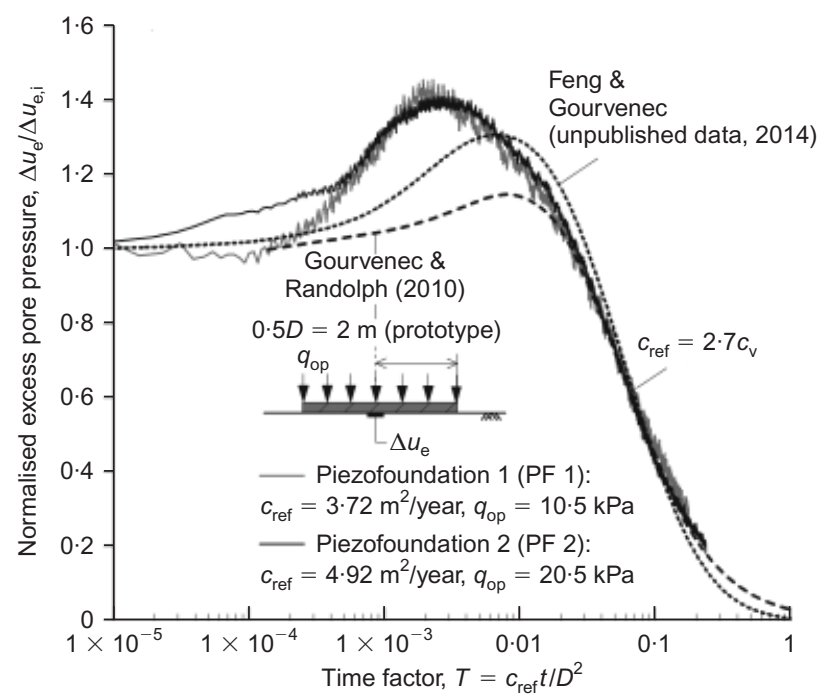

Fig. 6. Normalised excess pore pressure under a 'piezofoundation', $\Delta u_{\mathrm{e}} / \Delta u_{\mathrm{e}, \text { in }}$, plotted against time factor, $T=c_{\mathrm{ref}} t / D^{2}$

\section{MUDMAT LOADING TESTS}

The sliding tests with the model mudmat foundation involved three elements: (a) touchdown of the foundation, followed by consolidation under self-weight; (b) sliding events, performed at a rate to achieve an undrained soil response; and (c) periods of reconsolidation between the sliding cycles. A time history of the applied vertical load and horizontal displacement during the tests is illustrated in Fig. 7 and is summarised in Table 2.

\section{Mudmat installation}

Touchdown of the mudmat foundation was achieved by driving the vertical axis of the loading actuator at a slow rate of $0.01 \mathrm{~mm} / \mathrm{s}$ until the required (compressive) vertical load was recorded on the load cell. The vertical axis of the actuator was locked to load-control mode after touchdown and achievement of the required vertical load in order to ensure that a constant operative vertical bearing pressure, $q_{\mathrm{op}}$, was imposed on the seabed throughout the test (Fig. 7(a)).

Values of $q_{\text {op }}$, which represent the self-weight of the fully submerged foundation and the equipment that the mudmat supports, were determined as a percentage of the predicted ultimate vertical bearing capacity, $q_{\mathrm{u}}=N_{\mathrm{cv}} s_{\mathrm{um}}$ of the model foundation, where $N_{\mathrm{cv}}$ is the bearing capacity factor relevant to the non-dimensional shear strength heterogeneity index, $k B / s_{\text {um }}$, with $k$ being the gradient of undrained shear strength with depth. An $N_{\mathrm{cv}}$ of 11.66 was used based on results of finite-element analysis of the bearing capacity of a roughbased surface foundation with $B / L=0.5$ (Feng et al., $2014 b$ ). Two different values of $q_{\text {op }}$ were considered,

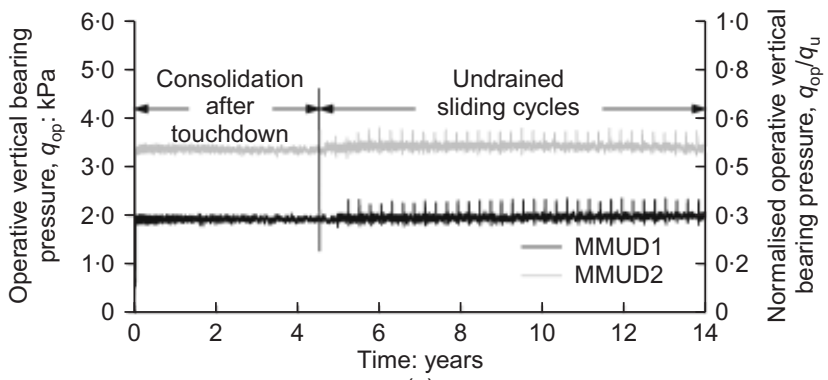

(a)

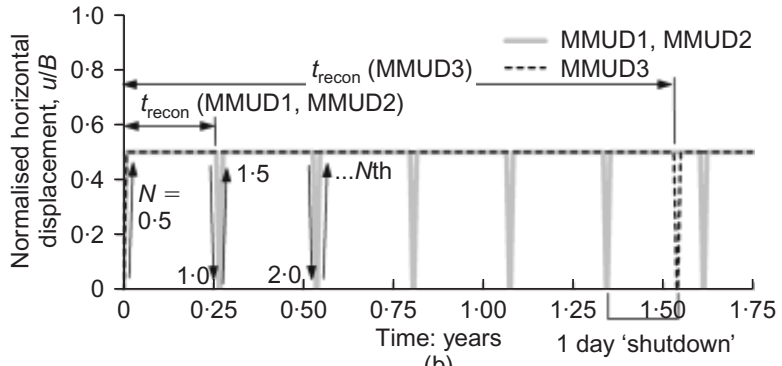

(b)

Fig. 7. Time histories (in prototype scale) of: (a) operative vertical bearing pressure, $q_{\mathrm{op}}$, and ratio of operative to ultimate vertical bearing capacity, $q_{\mathrm{op}} / q_{\mathrm{u}} ;$ (b) normalised horizontal displacement, $u / B$ during loading cycles

Table 2. Centrifuge test programme

\begin{tabular}{l|l|c|c|c}
\hline Parameters & $\begin{array}{l}\text { Units in prototype } \\
\text { scale }\end{array}$ & MMUD1 & MMUD2 & MMUD3 \\
\hline Ultimate vertical bearing pressure, $q_{\mathrm{u}}=N_{\mathrm{cv}} s_{\mathrm{um}}$ & $\mathrm{kPa}$ & $6 \cdot 18$ & $6 \cdot 18$ & $6 \cdot 18$ \\
Target operational vertical bearing pressure ratio, $q_{\mathrm{op}} / q_{\mathrm{u}}$ & - & - & $0 \cdot 3$ & $0 \cdot 5$ \\
Normalised horizontal displacement, $u / B$ & years & - & $0 \cdot 5$ & $0 \cdot 5$ \\
Reconsolidation period, $t_{\text {recon }}$ & - & 80 & $0 \cdot 25$ & $1 \cdot 5$ \\
Total number of slides & & 80 & 80 \\
\hline
\end{tabular}


corresponding to ratios of operational-to-ultimate bearing capacity, $q_{\mathrm{op}} / q_{\mathrm{u}}$ of 0.3 (MMUD1 and MMUD3) and 0.5 (MMUD2). These ratios are typical of field conditions, and are within a range that would be expected to cause a pure sliding mechanism in response to horizontal loading under undrained conditions (Green, 1954; Gourvenec \& Randolph, 2003; Cathie et al., 2008).

A consolidation period of 4.5 prototype years was allowed after touchdown of the mudmat (Fig. 7(a)). This period is equivalent to a time factor of $T \sim 0 \cdot 4$, which, based on Fig. 6 , would have been sufficient for $\sim 95 \%$ of excess pore pressures directly beneath the model foundation to have dissipated, bringing the soil beneath the foundation close to a fully consolidated state before the operational loading (sliding) began.

\section{Undrained cyclic sliding}

The cycles of undrained foundation sliding commenced after the initial self-weight consolidation period. As illustrated in Fig. 7(b), one cycle of sliding constitutes a pair of sliding movements of $u=0.5 B(2.5 \mathrm{~m}$ prototype scale $)$. A single slide represents a cycle number increment of $\Delta N=0 \cdot 5$, so the first forward and backward slides are denoted by $N=0.5$ and $N=1 \cdot 0$ respectively. A total of $N=40$ cycles was carried out during each mudmat test. Sliding was conducted at a rate of $v=1 \mathrm{~mm} / \mathrm{s}$. This loading rate corresponds to a one-way sliding duration of $t_{\text {slide }}=25 \mathrm{~s} \mathrm{(} 3$ days in prototype scale), equivalent to an elapsed time factor, $T_{\text {slide }}=c_{\text {ref }} t_{\text {slide }} / B^{2} \sim 0.001$. This duration is sufficiently short that negligible dissipation of excess pore water occurs in the soil beneath the foundation during sliding (based on the dissipation curve for vertical loading of a foundation shown in Fig. 6).

\section{Reconsolidation between sliding events}

A reconsolidation period, $t_{\text {recon }}=780 \mathrm{~s}$ in model scale $\left(0.25\right.$ years in prototype scale, $T_{\text {recon }}=c_{\text {ref }} t_{\text {recon }} / B^{2}$ of 0.02$)$ was prescribed after each forward slide before the subsequent backward slide during tests MMUD1 and MMUD2, while a longer intervening period of reconsolidation, $t_{\text {recon }}=4680 \mathrm{~s}$ ( 1.5 years in prototype scale, $T_{\text {recon }}=c_{\text {ref }} t_{\text {recon }} / B^{2}$ of 0.13 ) was prescribed in test MMUD3. The selected durations reflect a range of periods that a pipeline may remain in operation between scheduled shutdowns and thus the foundation will remain at the forward position, represented by the $0 \cdot 5 B$ movement from the original position (Fig. 7). The degree of consolidation taking place during the operational period, $T_{\text {recon }}$, can be closely approximated by the dissipation curve in Fig. 6 (where $t_{\text {recon }}$ of 0.25 and 1.5 years results to $\sim 10 \%$ and $\sim 70 \%$ pore pressure dissipation, respectively). A pause of $8 \mathrm{~s}$ in model scale (1 day in prototype scale) was included after each backward slide and before the next forward slide (Fig. 7(b)), representing a brief shutdown period when the pipe cools and contracts and the foundation returns to its original position. During the waiting periods, the foundation was prevented from moving horizontally, but was free to settle under the applied $q_{\text {op}}$.

\section{RESULTS AND DISCUSSION}

Horizontal resistance

Horizontal resistance mobilised during sliding is expressed in terms of a mobilised coefficient of sliding friction, $\mu$, given by equation (5)

$$
\mu=\frac{H}{V}
$$

where $H$ and $V$ are the horizontal and vertical loads between the foundation and the underlying soil. The variation of $\mu$ with normalised horizontal footing displacement, $u / B$, highlighting selected cycles for MMUD1, is shown in Fig. 8(a), with the recorded horizontal load, $H$, in Fig. 8(b). The resistance, $\mu$, for the first movement $(N=0 \cdot 5)$ for all three tests is shown in Fig. 8(c). The mobilised horizontal resistance reaches a peak at the extremities of a slide, but has a

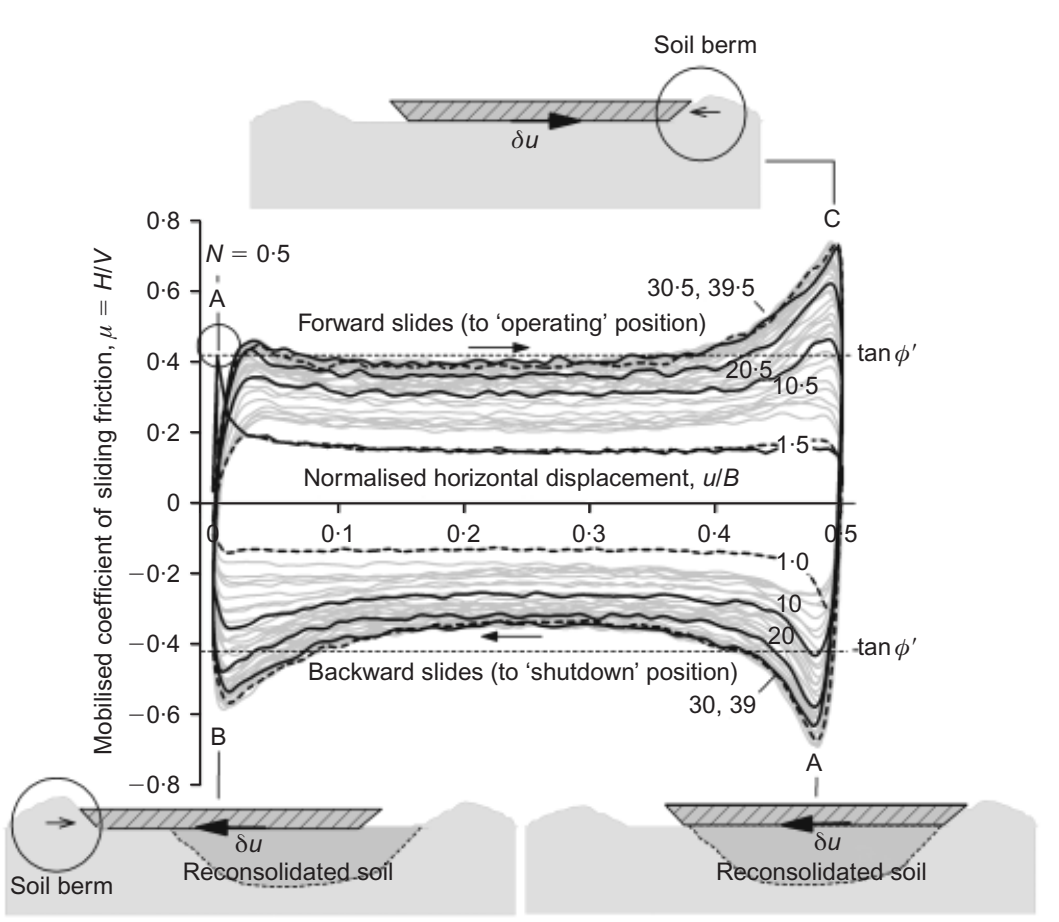

(a)

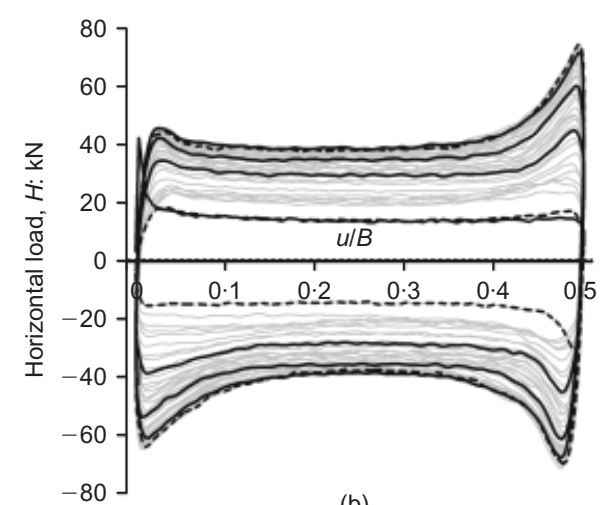

(b)

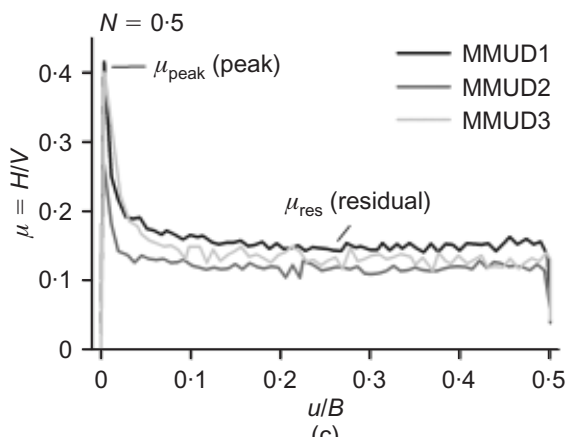

(c)

Fig. 8. (a) Mobilised coefficient of sliding friction, $\mu=H / V$, plotted against normalised horizontal footing displacement, $u / B$, for all loading cycles during MMUD1 test; (b) mobilised horizontal loads, $H$, plotted against normalised horizontal footing displacement, $u / B$, during MMUD1 test; (c) mobilised coefficient of sliding friction, $\mu=H / V$, during first slide of MMUD1, MMUD2 and MMUD3 tests 
steady residual value over the majority of the sliding movement. The steady residual value increases with loading cycles.

The peak resistances are identified in Fig. 8(a) by the labels A-C. Peak A reflects an increased sliding resistance due to consolidation of the underlying soil after a period of consolidation - at the start of the forward slide in the first cycle following set down and at the start of the reverse slide in each cycle. Peaks B and C are due to the interaction of the mudmat ski with the soil berms that build up at the limits of the movement.

Mobilised resistance during first slide. The residual resistance during the first slide of each test (Fig. 8(c)), expressed as an equivalent friction coefficient, was approximately within $H_{\text {res }, N=0.5} / V$ of $0 \cdot 11-0 \cdot 14$, which is comparable to the normally consolidated strength ratio of $0 \cdot 15$ for the soil sample, interpreted from the T-bar and moisture content tests. It is perhaps surprising that the T-bar strength ratio $s_{\mathrm{u}} / \sigma_{\mathrm{v} 0}^{\prime}$ and $H_{\text {res }, N=0.5} / V$ are so similar, given the high sliding distance and therefore shear strain beneath the foundation, but it appears that the two mechanisms generated comparable levels of excess pore pressure. On the other hand, the initial peak gave approximately double the resistance, but was extremely brittle.
Mobilised resistance in cycles of sliding. To quantify the variation in sliding resistance with continued cycles of sliding, the steady residual value, $H_{\text {res,cyc }}$, at $u / B=0.25$ is used. The horizontal resistance variation factor, $\Delta \mu=H_{\text {res,cyc }} / H_{\text {res }, N=0.5}$, and equivalent friction coefficient, $\mu_{\text {res }}=H_{\text {res,cyc }} / V$, are plotted against cycle number, $N$, and time factor, $T_{\mathrm{op}}=c_{\text {ref }} t_{\mathrm{op}} / B^{2}$, in Figs 9 (a) and 9(d), where $t_{\mathrm{op}}$ is the accumulated operational time, which includes all undrained sliding and reconsolidation events.

The trend of increasing $\Delta \mu$ with $N$ or $T_{\mathrm{op}}=c_{\mathrm{ref}} t_{\mathrm{op}} / B^{2}$ indicates that the loss of strength during the shearing process (sliding) is surpassed by the regain in strength of the soil beneath the mudmat foundation during the intervening reconsolidation periods. In all tests, the residual sliding resistance rises by a factor of 3-4 with continued cycles of shearing and reconsolidation (Figs 9(a) and 9(b)). The long-term sliding resistance approaches a drained value, which can be estimated as $\tan \phi^{\prime}=0.42$, where $\phi^{\prime}=23.5^{\circ}$ is the internal angle of friction (Figs 9(c) and $9(d))$. This represents the state at which the soil beneath the foundation has undergone sufficient cycles of sliding, pore pressure generation and reconsolidation to reach the critical state and eliminate any tendency for contraction and further excess pore pressure generation. Depending on the duration of each cycle, this evolution may occur in a single cycle or progressively through multiple episodes of sliding

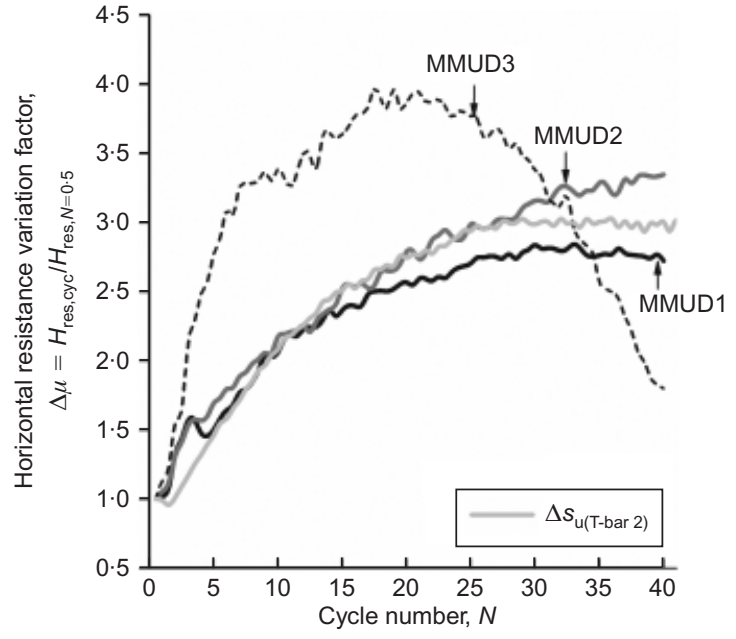

(a)

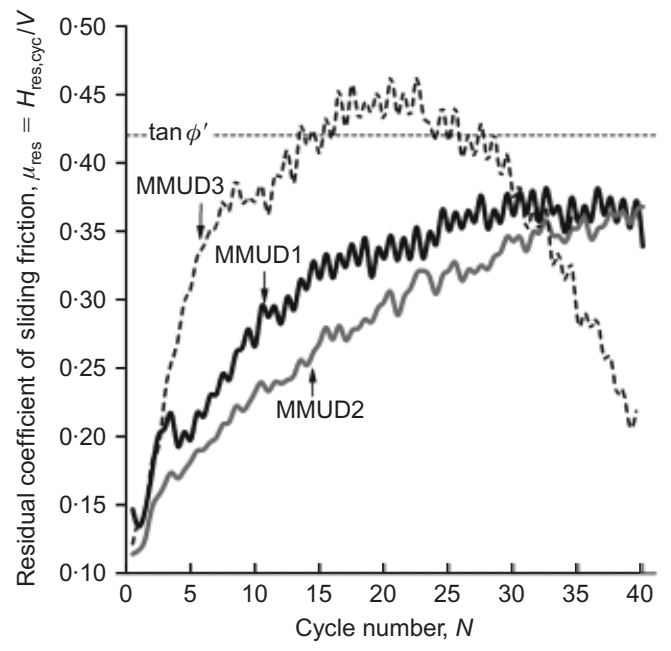

(c)

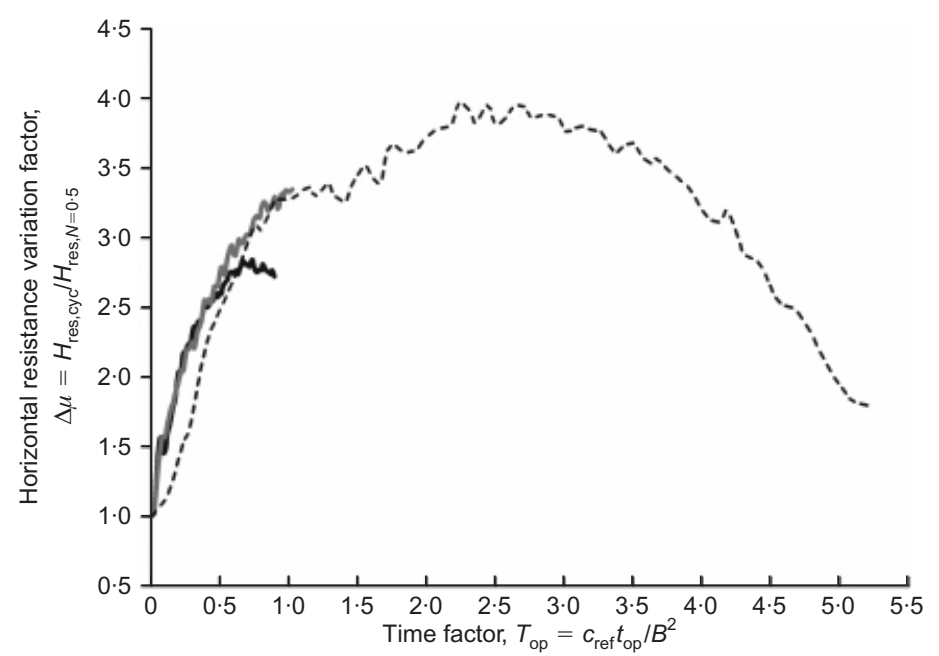

(b)

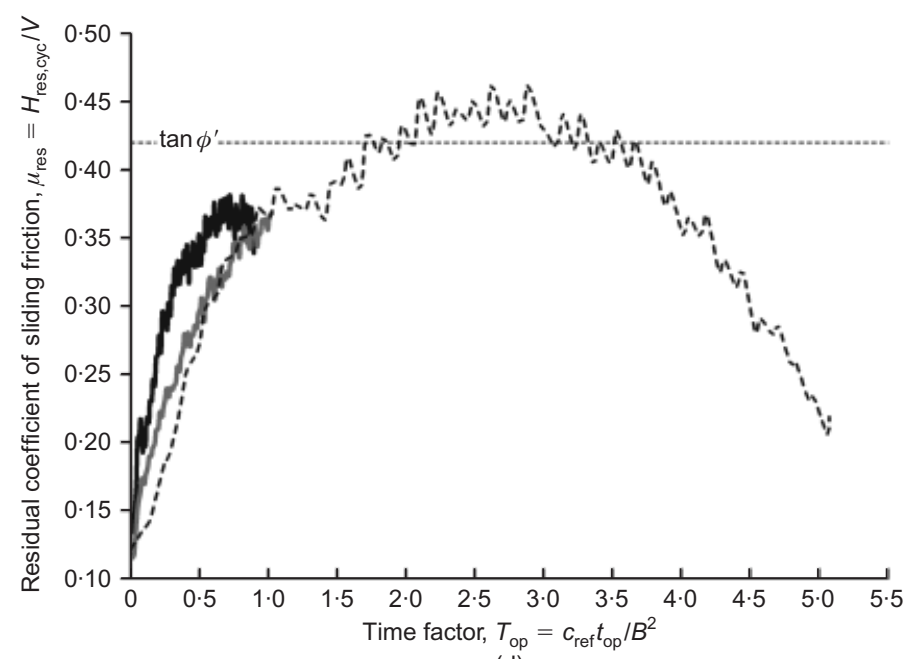

(d)

Fig. 9. Horizontal resistance variation factor, $\Delta \mu=H_{\text {res,cyc }} / H_{\text {res, }, N=0.5}$ plotted against: (a) cycle number, $N$ and (b) accumulated time factor, $T_{\mathrm{op}}=c_{\mathrm{ref}} t_{\mathrm{op}} / B^{2}$; and residual coefficient of sliding friction, $\mu_{\text {res }}=H_{\text {res,cyc }} / V$ plotted against: (c) cycle number, $N$ and (d) accumulated time factor, $T_{\mathrm{op}}=c_{\mathrm{ref}} t_{\mathrm{op}} / B$ 
and consolidation, as similarly observed on pipe-soil interaction reported in White et al. (2012), Randolph et al. (2012) and Yan et al. (2014).

There is remarkable similarity between the cyclic hardening from the episodic T-bar $\left(\Delta s_{\mathrm{u}}\right.$ from Fig. $4(\mathrm{~d})$, which is also shown on Fig. 9(a)), and the mudmat tests. The underlying behaviour is the same - successive cycles of undrained failure, either through remoulding (T-bar) or shearing (mudmat), followed by pore pressure dissipation under a total stress level that is approximately constant after each cycle (overburden stress in the T-bar test, and $q_{\text {op }}$ in the mudmat tests). In both cases, the soil begins in a normally consolidated state and approaches the critical state for that controlling stress. A simple theoretical estimation of this rise in strength, considering a single soil element and original Cam Clay, would be $\exp (1-\kappa / \lambda) \sim 2 \cdot 2$. This is slightly lower than the observed rise, probably because the high strain shearing process generates greater excess pore pressure than implied by the original Cam Clay spacing ratio $(e=2 \cdot 8)$ (White \& Hodder, 2010).

The drained or critical state is reached in fewer cycles when a longer reconsolidation time is adopted. The time factor normalisation (equation (4)) provides closer alignment of the results from all three tests (Figs 9(b) and 9(d)). The drained limit of $\mu_{\text {res }} \sim \tan \phi^{\prime}$ is reached within a time factor

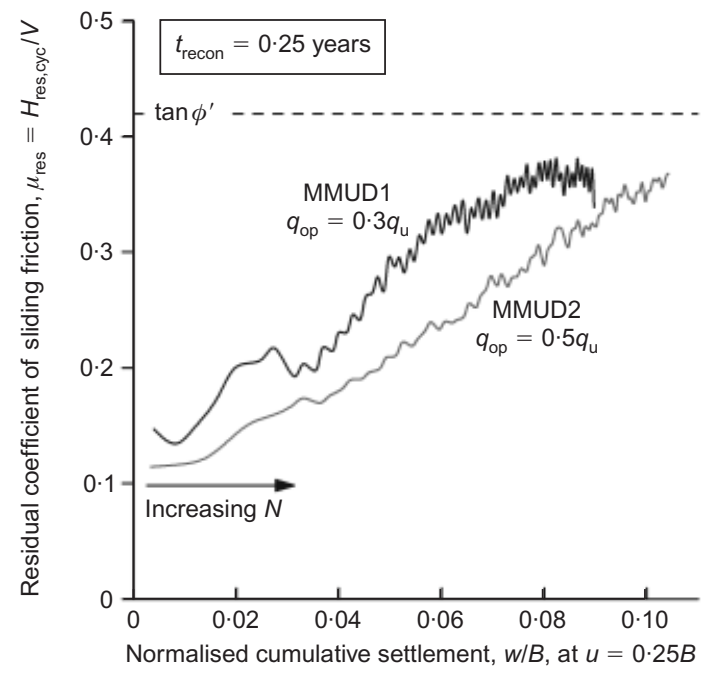

(a)

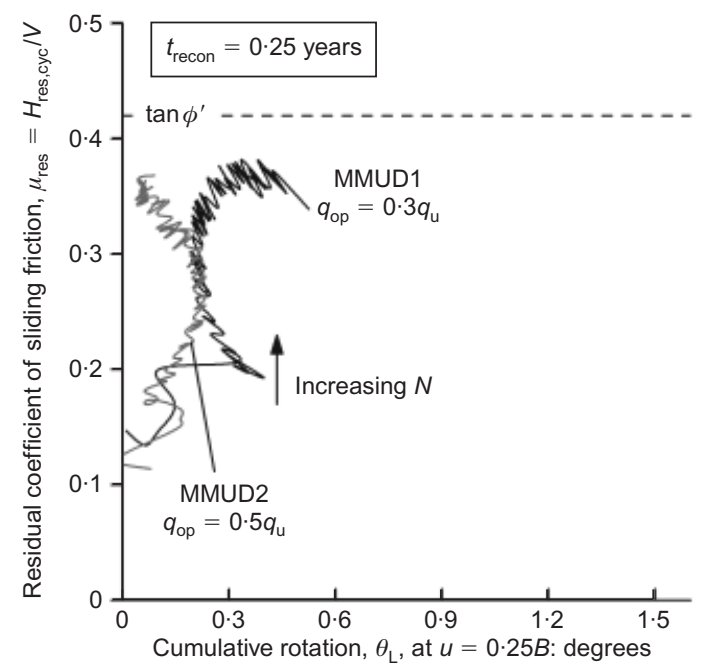

(c) of $T_{\mathrm{op}} \sim 1 \cdot 0$. This is more rapid dissipation compared to purely vertical loading (for which $T_{90} \sim 2$ in Booker \& Small (1986)), which can be attributed to the smaller zone of shearing, therefore the shorter drainage length during sliding failure compared to vertical loading.

During the final stage of test MMUD3, the residual sliding resistance began to fall. This transition is attributed to a changing distribution of contact between the mudmat and the seabed, and is discussed later.

\section{Foundation settlements}

The cumulative foundation settlements at the RP normalised by footing breadth are presented in Figs 10(a) and 10(b). These values are taken at the mid-point of each sweep, $u / B=0 \cdot 25$, and are compared against the mobilised sliding friction, $\mu_{\text {res }}=H_{\text {res,cyc }} / V$. The full RP settlement history of each test is plotted against the normalised horizontal displacement of the foundation, $u / B$, in Fig. 11. The incurred settlements are greater for the heavier mudmat (Fig. 10(a), Fig. 11(b)), as would be expected.

A more subtle observation is that the prolonged intervening reconsolidation period reduces the incurred settlements for a given number of cycles (Fig. 11(c)). This shows that the gain in strength due to consolidation causes the

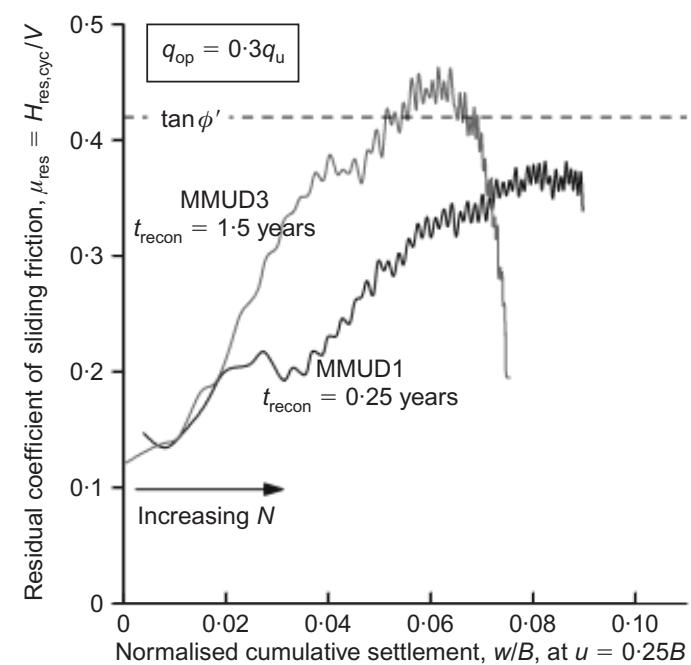

(b)

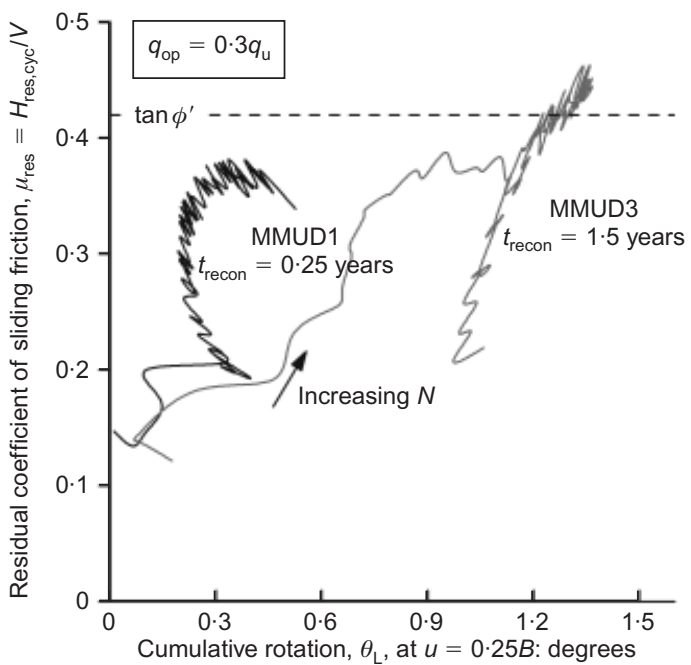

(d)

Fig. 10. (a), (b) Cumulative settlements normalised by footing breadth, $w / B ;$ (c), (d) cumulative rotation about the short axis, $\theta_{L}$, observed half-way along the total sliding distance (i.e. at $u / B=0 \cdot 25$ ), plotted against residual coefficient of sliding friction, $\mu_{\text {res }}=H_{\text {res,cyc }} / V$ 
undrained settlement within each sliding movement to be reduced (Fig. 10(b)). Therefore, although the extended rest period between cycles allows a greater level of consolidation settlement, the undrained settlements incurred during each sliding movement are reduced.

The mudmat movement and consolidation periods create a settlement bowl that slopes downwards towards the operating position, as shown in Fig. 11. The slope forms during the early cycles due to the soil surface geometry caused by the initial ploughing action. The asymmetry is sustained by the greater consolidation settlement that accumulates at the 'operating' limit compared to the 'shutdown' limit. The inclination of the mudmat movement during sliding reaches $0 \cdot 5-0 \cdot 85^{\circ}$ by the end of the tests, which is relatively small compared to common design tolerances. However, the cumulative settlement is approximately $10 \%$ of the foundation breadth, which is very significant and likely to be more onerous on connection integrity than the rotation.

The foundation settlement during the reconsolidation periods (i.e. the 'operating' periods) of cycles 1,10 and 40 is shown in Fig. 12. The $0 \cdot 25$ years reconsolidation period is insufficient to reach the full consolidation settlement during cycle 1 , with approximately $60 \%$ additional settlement projected to be mobilised after the 1.5 years reconsolidation period. By the tenth and 40th cycles, all three cases show a stiffer response, with a reduced level of incremental consolidation settlement. The rate of settlement increases during these later cycles, reflecting a rise in $c_{\text {ref }}$ due to the changing stiffness, with 0.25 years rest period being sufficient for the consolidation settlement to stabilise.

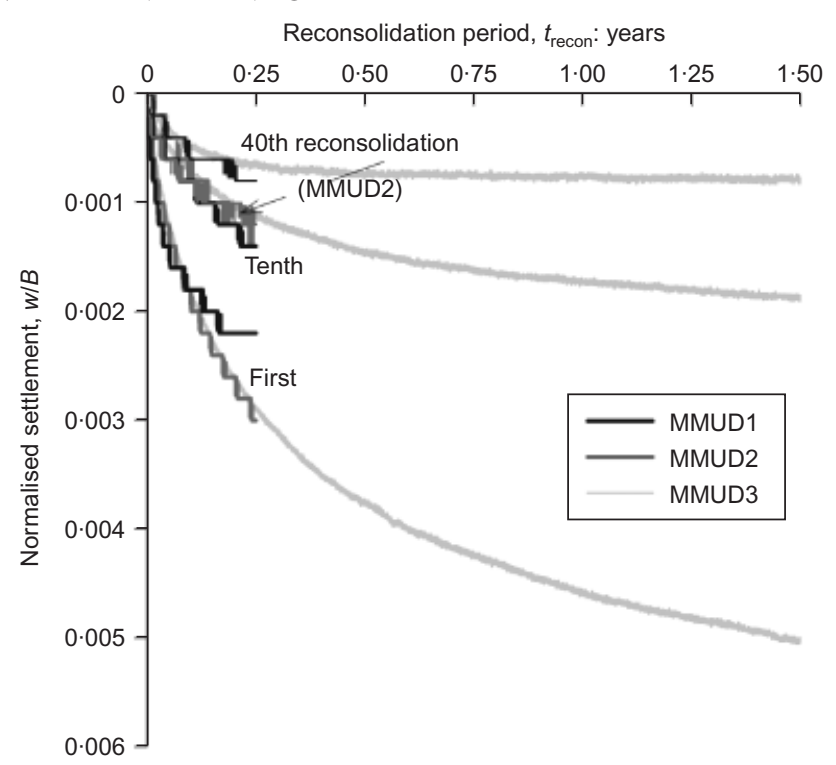

Fig. 12. Consolidation settlements incurred during intervening rest periods at 'operating' position normalised by foundation breadth, $B$, plotted against time (prototype scale) for loading cycles $N=1,10$ and 40

\section{Foundation rotation}

The settlements of the foundation viewed perpendicular to the sliding direction are presented in Fig. 13 at the 'shutdown' and 'operating' positions $(u / B=0$ and $0 \cdot 5$, respectively) for selected sliding cycles of the three tests. This

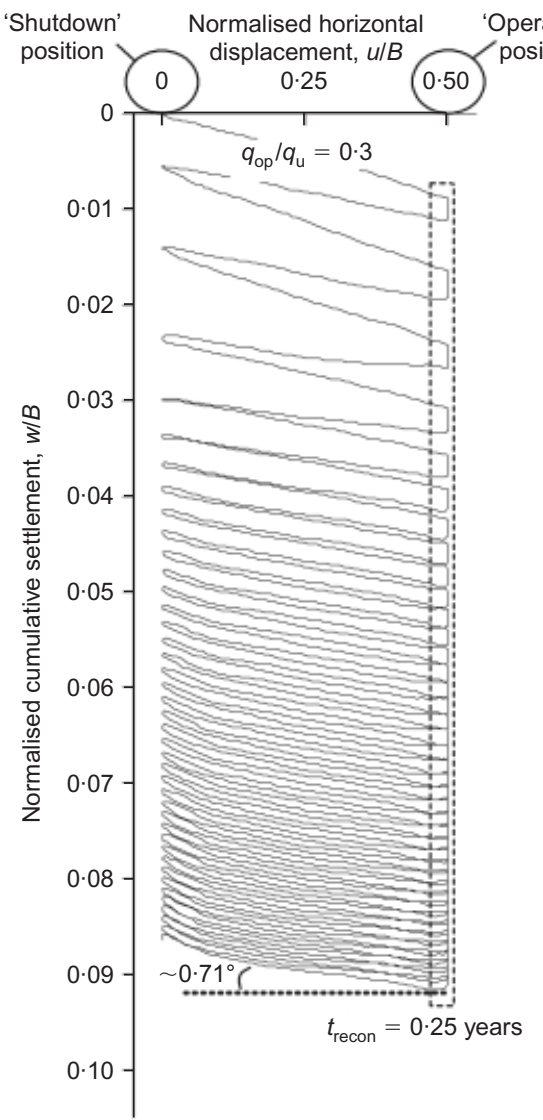

(a)

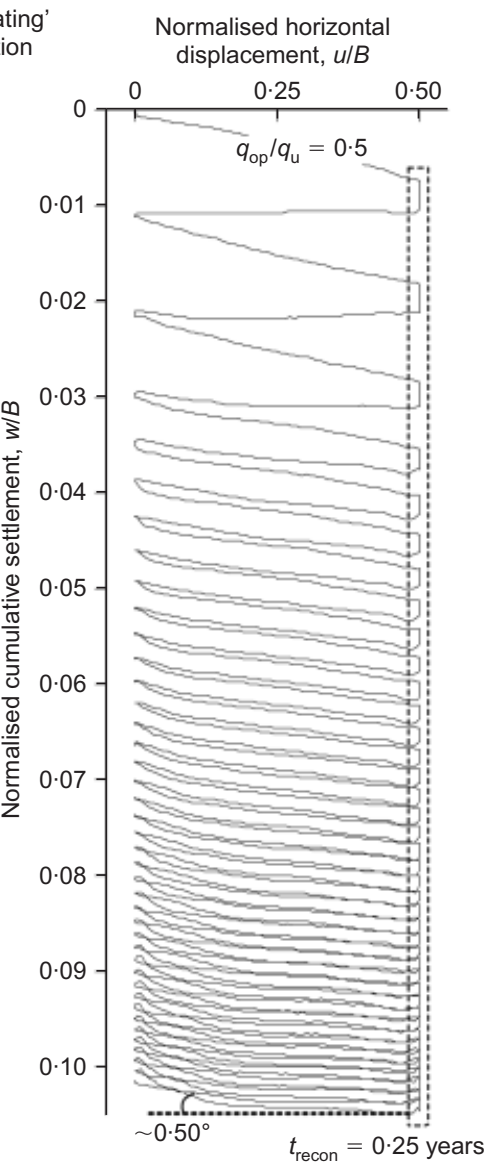

(b)

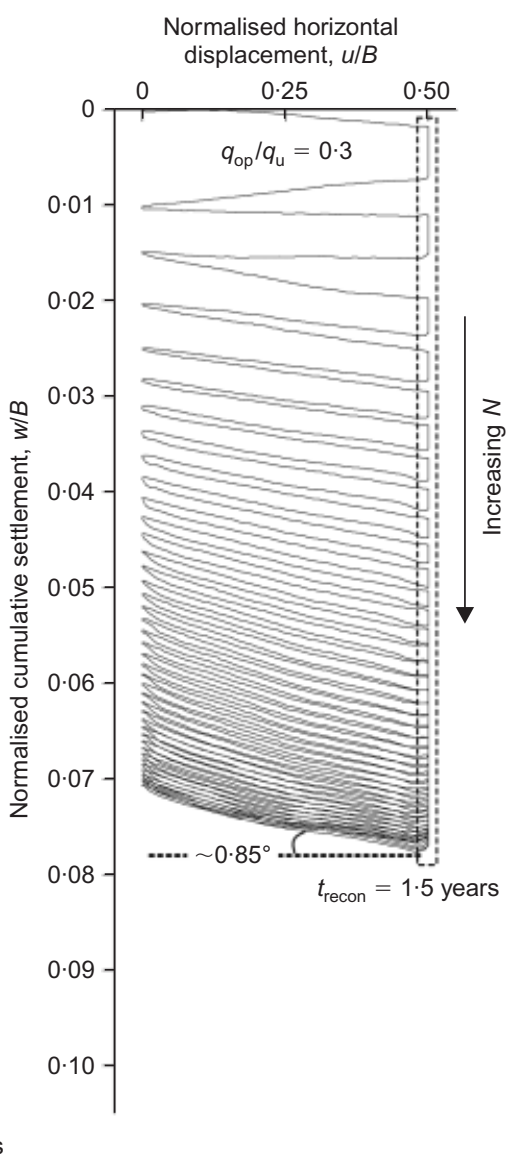

(c)

Fig. 11. Cumulative settlements observed during episodes of sliding and intervening rest periods normalised by footing breadth plotted against normalised horizontal displacement, $u / B$, for tests: (a) MMUD1; (b) MMUD2; (c) MMUD3 


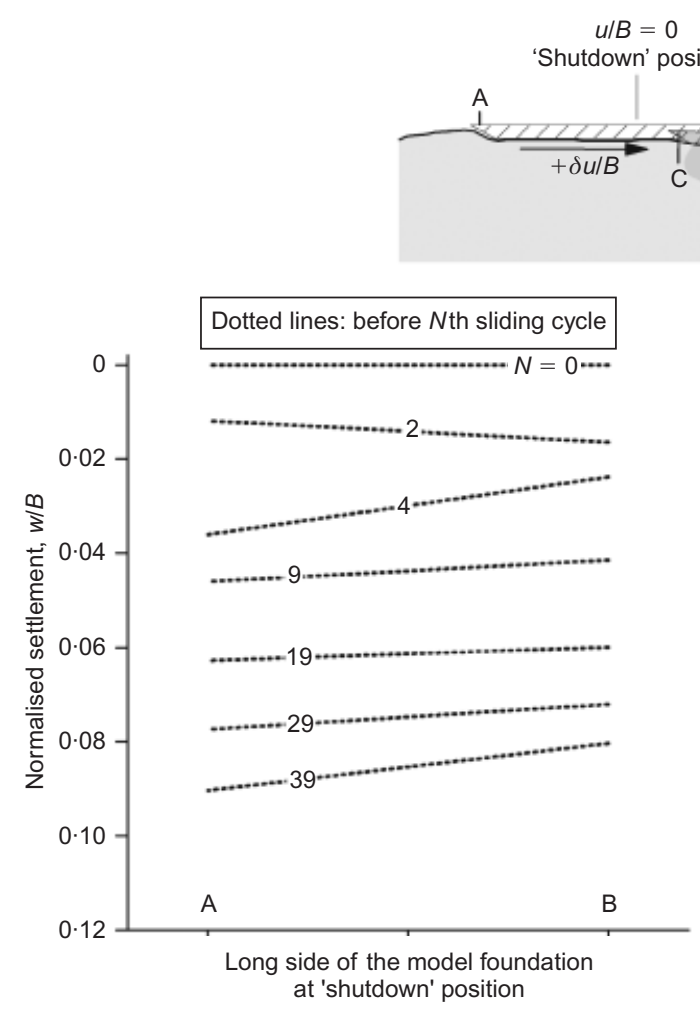

$$
\begin{gathered}
u / B=0.5 \\
\text { 'Operating' position }
\end{gathered}
$$
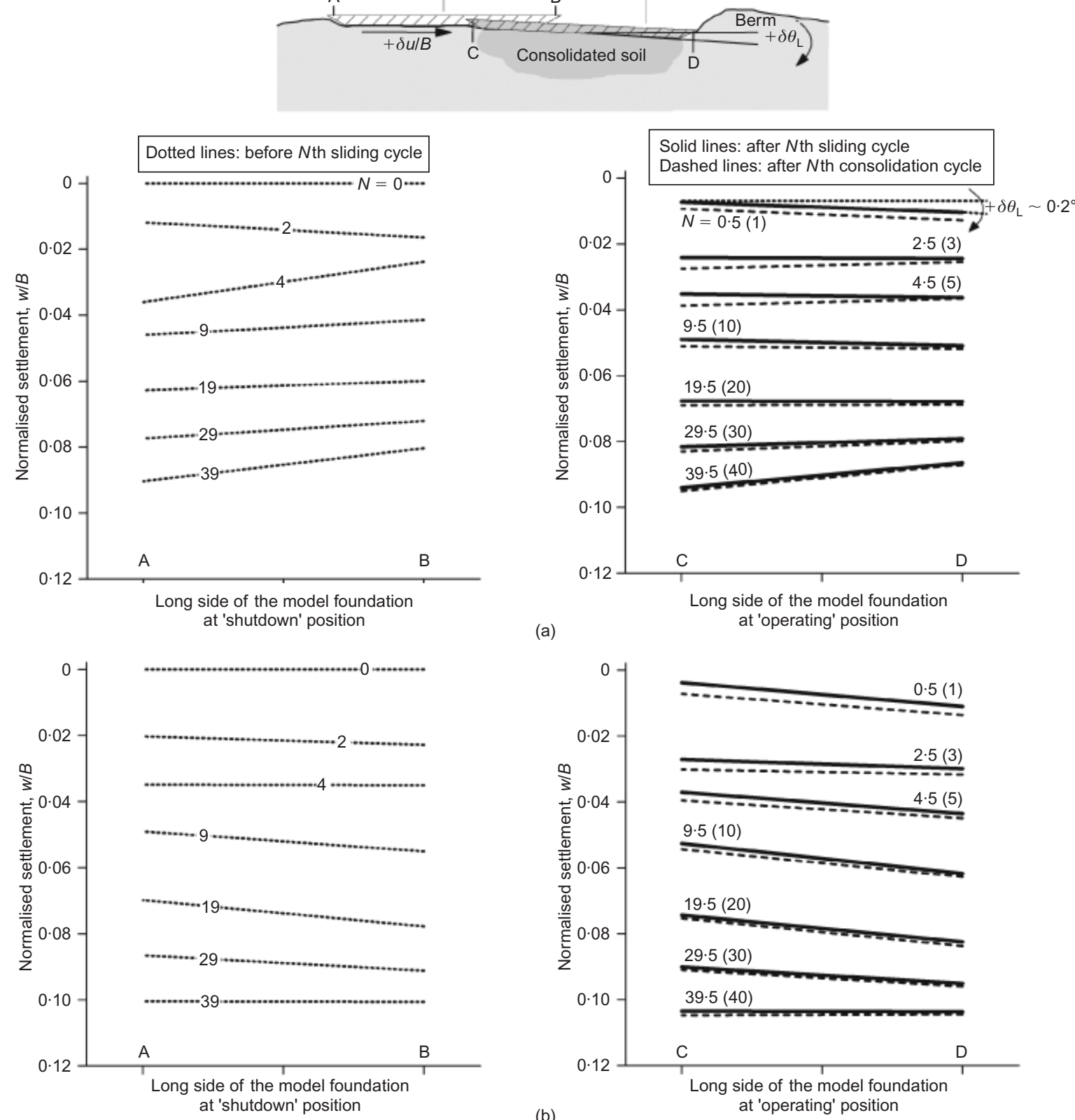

(a)
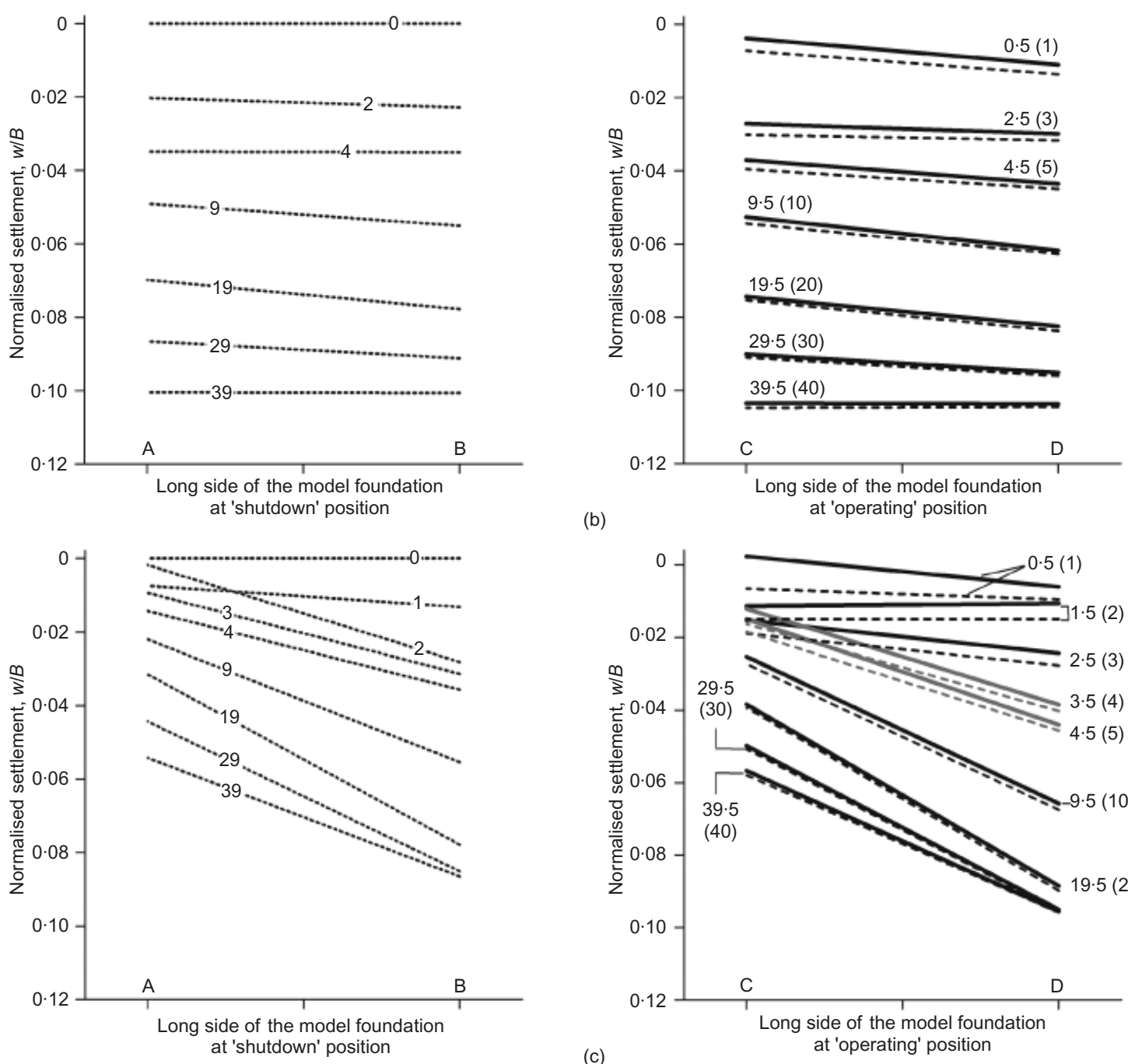

(b)

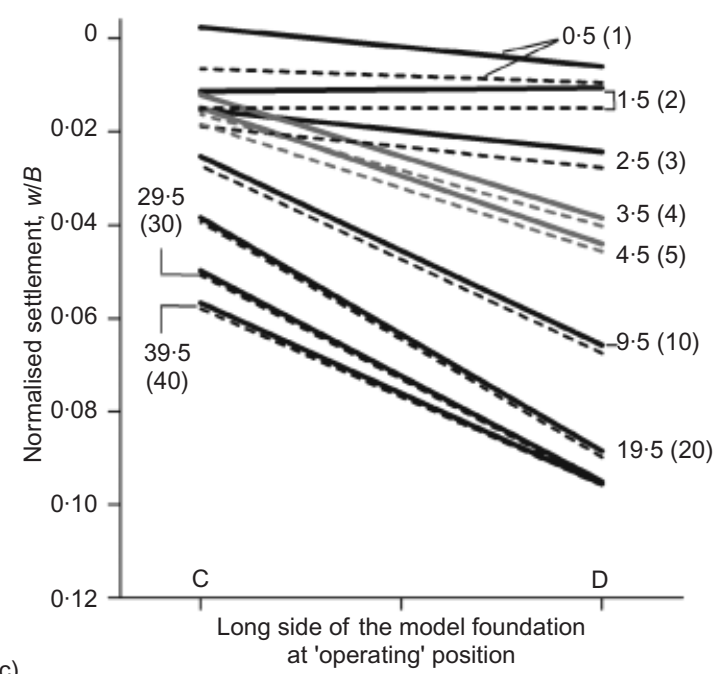

(c)

Fig. 13. Orientation of the long side of the model foundation at the 'shutdown' and 'operating' positions at selected sliding cycles during: (a) MMUD1; (b) MMUD2; (c) MMUD3 tests 
portrayal of the settlement data shows the rotation of the foundation about the short axis, $\theta_{L}$, which is plotted against $\mu_{\text {res }}$ for values at $u / B=0.25$ in Figs $10(\mathrm{c})-10(\mathrm{~d})$. In general, the cumulative rotation incurred in any of the tests is very small, with maximum values of $\theta_{L}<0.4^{\circ}$ in tests MMUD1 and MMUD2 (Fig. 10(c)), and $<1 \cdot 5^{\circ}$ in MMUD3 (Fig. $10(d))$.

Figure 13 shows that the leading edge of the foundation tipped down at an angle of $\theta_{L} \sim 0.2^{\circ}$ as the foundation translated for the first time to a weaker patch of soil $(N=0 \cdot 5)$. This resulted in ploughing of soil ahead of the foundation, establishing berms, as evidenced in Fig. 14.

The rotation $\theta_{L}$ occurs concurrently with undrained settlements during the sliding movements of the foundation. During the reconsolidation periods, minimal further rotation occurs. A subtle observation in Fig. 13 is that the rotation incurred during early cycles of sliding is reduced during the following reconsolidation period. The trailing end of the foundation in the operating position, which can be considered to be sitting on the 'free' soil surface, settled at a faster rate compared to at the leading edge, which is 'buried' at some depth. This differential rate in consolidation along the long axis of the foundation is possibly due to the difference in drainage path length for excess pore water dissipation at the opposite edges of the foundation. Build-up of soil berms next to the leading edge of the foundation at the operating position (Fig. 14) would have led to locally increased length of drainage path, resulting in slower consolidation and settlement at that side. A consequence of this is the levelling of the differential settlements during the 'operating' period, which mitigated the accumulation of rotation.

The first few episodes of reconsolidation incurred large consolidation settlements, particularly for the extended reconsolidation period (MMUD3 in Fig. 12). As a result, soil berms also formed at the 'free' side of the foundation (peripheries of side $\mathrm{C}$ in Fig. 13) during the early cycles of reconsolidation. The foundation is seen to override this soil berm as it translated back to its original position during shutdown after the second reconsolidation episode in MMUD3, as evidenced by a steep increase in rotation of $\delta \theta_{L} \sim 0 \cdot 5^{\circ}$ during $N=2 \cdot 0$ (Fig. 13(c)).

The foundation footprint in the 'operating' position (i.e. after the forward slide) continued to deepen with increasing settlements during the reconsolidation periods, exacerbating the cumulative rotation with ensuing sliding cycles (Figs $10(\mathrm{~d})$ and 13(c)). As the foundation translates from the 'shutdown' to the 'operating' position, the leading edge of the foundation tips down to the deepened soil. Over time, and through repetitive cycles of reconsolidation, the soil at the 'operating' position strengthened and eventually the rate of sinkage lessened and the rotation stabilised.

In test MMUD3 the cumulative rotation reached a peak value of $\theta_{L} \sim 1.5^{\circ}$ at the end of the 20th loading cycle, corresponding to $T_{\mathrm{op}}=2 \cdot 5$, and decreased afterwards. This achievement of peak $\theta_{L}$ triggered the decline of the sliding resistance with time during $T_{\mathrm{op}}>2.5$ (Fig. 9(b)). To understand the foundation behaviour during this time, foundation settlements at different increments of normalised horizontal displacement, $\delta u / B$, and incurred incremental rotation, $\delta \theta_{L}$, during $N=29.5$ are presented in Figs 15(a) and 15(b), respectively.

During the sliding movement in later cycles, the leading edge of the foundation settled at a higher rate than the opposite (trailing) edge, as shown in Fig. 15(a) for $N=29 \cdot 5$. The figure confirms that, at different stages of $\delta u / B$, a portion of foundation base slightly lifted off from the soil footprint: at the trailing side during $0<\delta u / B<0.4$ (positive $\delta \theta_{L}$ in Fig. 15(b)), and at the leading side during $0.4<\delta u / B<0.5$ when the foundation skis impacted against the berms at the terminating end of the slide (negative $\delta \theta_{L}$ in Fig. 15(b)).

The partial loss of basal contact during the sliding movements in test MMUD3 for $N>20$ resulted in load being concentrated on only part of the foundation underside, including on the skis. This concentration of load raises the
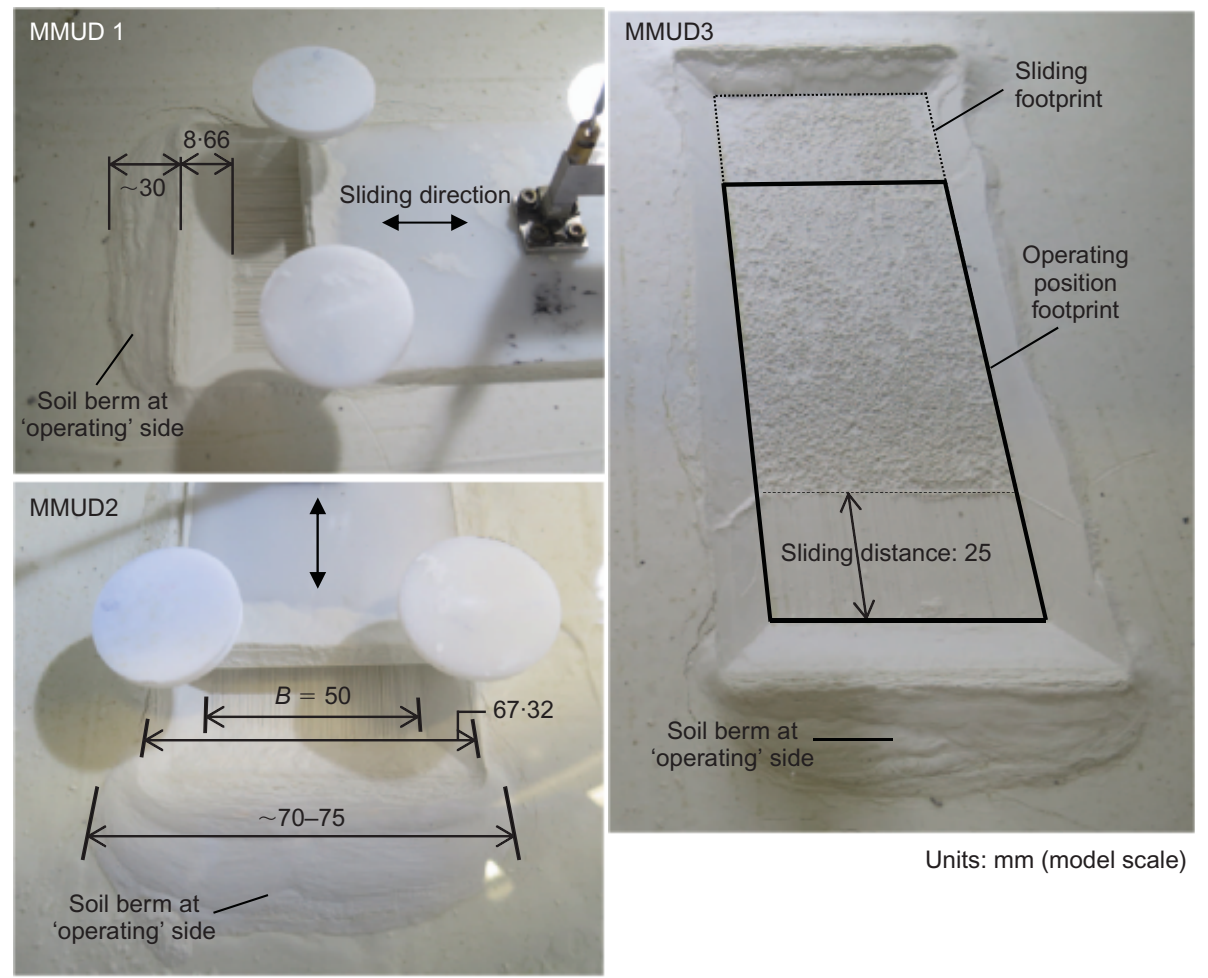

Units: $\mathrm{mm}$ (model scale)

Fig. 14. Formation of soil berm at extremities of the foundation footprint 


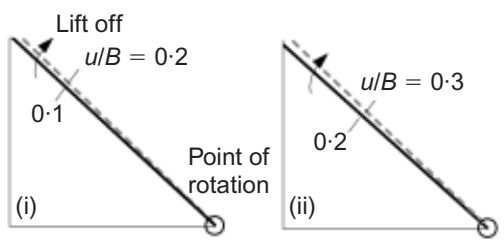

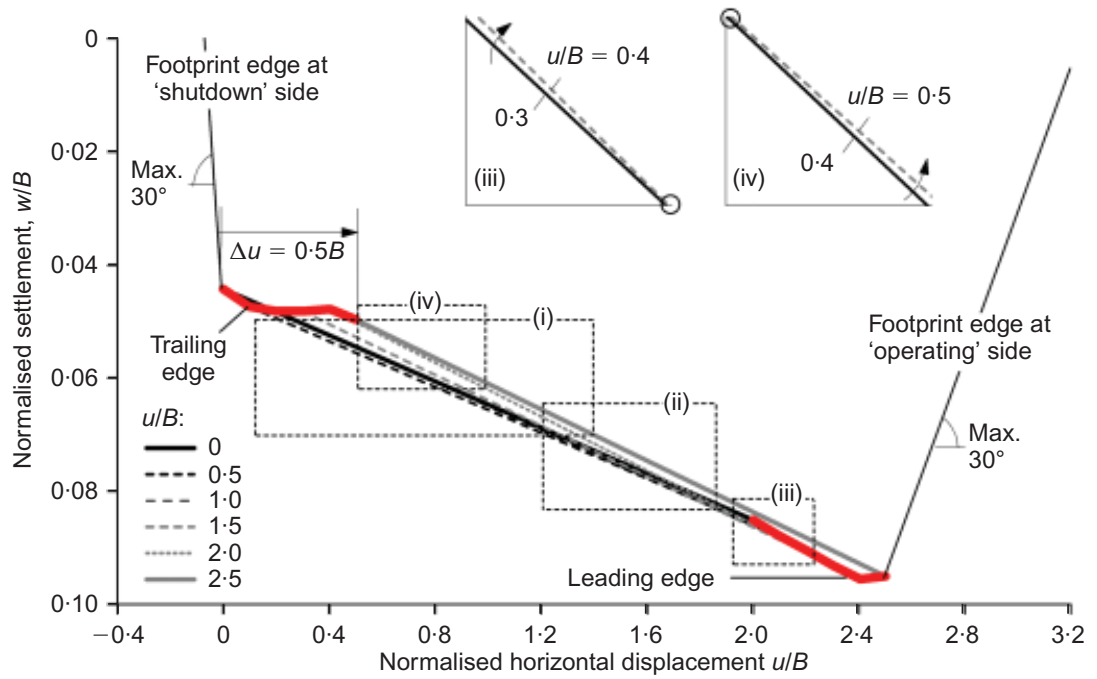

(a)

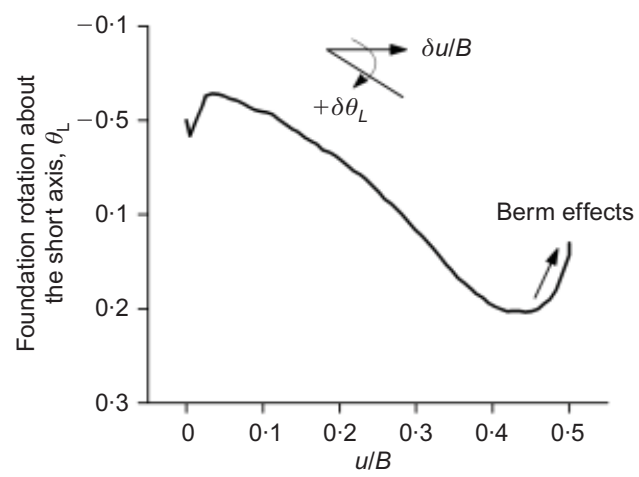

(b)

Fig. 15. (a) Orientation of long side of foundation; (b) incremental rotation, $\theta_{L}$, during slide $N=29 \cdot 5$ in MMUD3 test

contact stress and therefore creates new excess pore pressure. As a result, the stable sliding resistance corresponding to the drained value is no longer attained, resulting in the decline of the sliding resistance during this time (Fig. 9).

\section{FINAL REMARKS}

The potential of a tolerably mobile mudmat foundation to support subsea pipeline infrastructure was investigated. A rectangular mat foundation provided with sloping sides, or 'skis', to encourage sliding, was translated laterally over the surface of soft clay relevant to many deep-water seabed soils. During translation, the foundation was unconstrained against settlement or rotation in any orientation. Undrained sliding cycles replicating the dynamics associated with thermal expansion and contraction of the attached subsea pipelines were modelled at correct prototype stress levels and over typical durations. Results presented highlighted changes in sliding resistance, settlements and rotation of the foundation during sliding cycles and intervening periods of reconsolidation between loading cycles.

Sliding resistance was observed to increase with increasing cycles of sliding and reconsolidation. This increase is primarily due to the regain in soil strength achieved during periods of rest between successive pipe operations, during which time dissipation of excess pore pressure results in a reduction in the moisture content and consequential increase in the undrained shear strength of the soil in the vicinity of the foundation. Current results showed that this regain in undrained shear strength during reconsolidation surpassed the loss of strength associated with soil shearing and reduction of effective stress during undrained sliding cycles.

The regain in undrained shear strength is controlled by the operative vertical bearing pressure carried by the foundation, and the duration of the reconsolidation period between sliding cycles. Increase in foundation bearing pressure, and extended rest periods between sliding cycles, resulted in a greater increase in sliding resistance over time. Long-term sliding resistance approached a drained value, which can be estimated by an equivalent mobilised coefficient of sliding friction given by the internal soil friction angle at critical state.

Undrained settlements associated with sliding were found to increase with increase in foundation bearing pressure. Extended rest periods between operational cycles resulted in a decrease in undrained settlements incurred during sliding.

Foundation rotation was incurred simultaneously with mobilisation of undrained settlements, but was seen to be small compared to common design tolerances for pipeline connections.

Foundation sliding displaced soil towards each end of the sliding footprint, creating berms. The formation of the berms significantly affected the foundation movements during sliding as a physical barrier and by increasing the drainage path length to one edge of the foundation.

Over time, extended rest periods caused a progressive sloping of the foundation footprint. A partial loss of contact between the foundation and the soil was instigated when the relative difference between the slope of the footprint at the 'shutdown' and 'operating' positions became sufficiently large. This loss of contact resulted in a decline of sliding resistance with time. The presence of the foundation skis was seen to constrain the rotation of foundation during sliding as it impacted on the soil berms that were deposited around the foundation footprint.

The reported study has identified key aspects of foundation design and operational conditions that affect the response of a sliding foundation. Significantly, the study has demonstrated that settlement between sliding events is more significant than foundation rotation, such that excess pore pressure generated during sliding and subsequent dissipation during reconsolidation control the tolerability of performance of the mobile foundation. The results demonstrate the potential for tolerably mobile foundations to support subsea pipeline infrastructure for offshore oil and gas development.

\section{ACKNOWLEDGEMENTS}

This work forms part of the activities of the Centre for Offshore Foundation Systems (COFS), currently supported as a node of the Australian Research Council Centre of 
Excellence for Geotechnical Science and Engineering and as a Centre of Excellence by the Lloyd's Register Foundation (LRF). The LRF helps to protect life and property by supporting engineering-related education, public engagement and the application of research. The work presented in this paper is supported through ARC grant (DP140100684) and this support is gratefully acknowledged.

\section{NOTATION}

$B$ foundation breadth

$c_{\mathrm{h}}$ horizontal coefficient of consolidation

$c_{\text {ref }}$ operative coefficient of consolidation

$c_{\mathrm{V}}$ vertical coefficient of consolidation

$D$ piezofoundation diameter

$e_{\mathrm{cs}}$ void ratio at $p^{\prime}=1 \mathrm{kPa}$ on $\mathrm{CSL}$

$G_{\mathrm{s}}$ soil particle density

$H$ horizontal load

$H_{\text {res,cyc }}$ residual resistance during sliding cycles

$H_{\text {res }, N=0.5}$ residual resistance during first slide

$I_{\mathrm{p}} \quad$ plasticity index of soil

$I_{\mathrm{r}}$ rigidity index of soil

$k$ gradient of undrained shear strength with depth

$k B / s_{\text {um }}$ non-dimensional shear strength heterogeneity index

$L$ foundation length

$M$ critical state friction constant

$N$ cycle number

$N_{\mathrm{cv}}$ bearing capacity factor

$q_{\mathrm{op}}$ operative vertical bearing pressure

$q_{\mathrm{T}-\mathrm{bar}}$ T-bar resistance

$q_{\mathrm{u}} \quad$ ultimate vertical bearing capacity

$R$ piezocone radius

$S_{\mathrm{t}}$ soil sensitivity

$s_{\mathrm{u}} \quad$ undrained shear strength

$s_{\mathrm{u}} / \sigma_{\mathrm{v} 0}^{\prime}$ normally consolidated strength ratio

$s_{\mathrm{u}, \mathrm{cyc}}$ undrained shear strength measured during cycles of penetration and extraction

$s_{\text {um }}$ mudline shear strength

$T$ non-dimensional time for dissipation $\left(c_{\text {ref }} t / B^{2}\right)$

$T^{*}$ non-dimensional time for interpretation of piezocone results $\left(c_{\mathrm{h}} t / R^{2} I_{\mathrm{r}}^{0 \cdot 5}\right)$

$T_{\text {op }}$ non-dimensional time for accumulated operational duration $\left(c_{\mathrm{ref}} t_{\mathrm{op}} / B^{2}\right)$

$T_{\text {recon }}$ non-dimensional time for reconsolidation period $\left(c_{\text {ref }} t_{\text {recon }} / B^{2}\right)$

$T_{\text {slide }}$ non-dimensional time for sliding duration $\left(c_{\text {ref }} t_{\text {slide }} / B^{2}\right)$

$T_{50}$ non-dimensional time for $50 \%$ pore pressure dissipation

$t$ dissipation time

$t_{\mathrm{op}}$ accumulated operational duration

$t_{\text {recon }}$ reconsolidation period

$t_{\text {slide }}$ sliding duration

$u$ horizontal displacement of foundation

$V$ vertical load

$v$ sliding rate

$w$ vertical displacement of foundation

$z$ depth

$z_{\mathrm{CPTu}}$ depth of piezocone tests

$\gamma^{\prime}$ average effective unit weight of the soil

$\Delta N \quad$ cycle number increment

$\Delta u_{\mathrm{e}} \quad$ excess pore pressure

$\Delta u_{\mathrm{e}, \mathrm{i}}$ initial excess pore pressure

$\Delta \mu$ horizontal resistance variation factor $\left(H_{\mathrm{res}, \mathrm{cyc}} / H_{\mathrm{res}, N}=0.5\right)$

$\Delta s_{\mathrm{u}} \quad$ strength variation factor $\left(s_{\mathrm{u}, \mathrm{cyc}} / s_{\mathrm{u}}\right)$

$\delta u$ incremental horizontal displacement of foundation

$\delta \theta_{L}$ incremental rotation of the foundation about the short axis

$\theta_{L}$ rotation of the foundation about the short axis

$\kappa$ slope of swelling line

$\lambda$ slope of normal consolidation line

$\mu$ mobilised coefficient of sliding friction

$\mu_{\text {res }}$ residual coefficient of sliding friction $\left(H_{\text {res,cyc }} / V\right)$

$v$ Poisson ratio

$\sigma_{\mathrm{v} 0}^{\prime} \quad$ in-situ effective vertical stress

$\phi^{\prime}$ internal angle of friction

\section{REFERENCES}

Acosta-Martinez, H. E. \& Gourvenec, S. M. (2006). One-dimensional consolidation tests on kaolin clay, Research Report GEO: 06385. Perth, Australia: Centre for Offshore Foundations Systems, School of Civil and Resource Engineering, The University of Western Australia.

Booker, J. R. \& Small, J. C. (1986). The behaviour of an impermeable flexible raft on a deep layer of consolidating soil. Int. $J$. Numer. Analyt. Methods Geomech. 10, No. 1, 311-327.

Bretelle, S. \& Wallerand, R. (2013). Fondations superficielles glissantes pour l'offshore profond - méthodologie de dimensionnement. In Proceedings of the 18th international conference on soil mechanics and geotechnical engineering (ICSMGE), Paris (eds P. Delage, J. Descrues, R. Frank, A. Peuch and F. Schlosser), pp. 2331-2334. Paris, France: Presses des Ponts (in French).

Butterfield, R., Houlsby, G. T. \& Gottardi, G. (1997). Standardized sign conventions and notation for generally loaded foundations. Géotechnique 47, No. 5, 1051-1054, http://dx.doi.org/10.1680/ geot.1997.47.5.1051, and corrigendum Géotechnique 48, No. 1, 157, http://dx.doi.org/10.1680/geot.1998.48.1.157.

Cathie, D., Morgan, N. \& Jaeck, C. (2008). Design of sliding foundations for subsea structures. In Proceedings of the 2nd $B G A$ international conference on foundations, Dundee, (ed. M. J. Brown), pp. 24-27. Bracknell, UK: IHS BRE press.

Chow, S. H., O’Loughlin, C. D. \& Randolph, M. F. (2014). Soil strength estimation and pore pressure dissipation for free-fall piezocone in soft clay. Géotechnique 64, No. 10, 817-827, http://dx.doi.org/10.1680/geot.14.P.107.

Cryer, C. W. (1963). A comparison of the three dimensional consolidation theories of Biot and Terzaghi. Q. J. Mech. Appl. Math. 16, No. 4, 401-412.

De Catania, S., Breen, J., Gaudin, C. \& White, D. J. (2010). Development of a multiple-axis actuator control system. In Proceedings of the international conference on physical modelling in geotechnics '10, Zurich (eds S. Springman, J. Laue and L. Seward), pp. 325-330. London, UK: Taylor and Francis Group.

Deeks, A., Zhou, H., Krisdani, H., Bransby, F. \& Watson, P. (2014). Design of direct on-seabed sliding foundation. In Proceedings of the 33rd international conference on ocean, offshore and arctic engineering, San Francisco, USA, paper V003T10A024, http:// dx.doi.org/10.1115/OMAE2014-24393. New York, NY, USA: ASME.

Dimmock, P., Clukey, E. C., Randolph, M. F., Gaudin, C. \& Murff, J. D. (2013). Hybrid subsea foundations for subsea equipment. $J$. Geotech. Geoenviron. Eng. 139, No. 12, 2182-2192, http:// dx.doi.org/10.1061/(ASCE)GT.1943-5606.0000944.

Feng, X., Gourvenec, S. \& Randolph, M. F. (2014a). Optimal skirt spacing for subsea mudmats under loading in six degrees of freedom. Appl. Ocean Res. 48, 10-20, http://dx.doi.org/10.1016/ j.apor.2014.07.006.

Feng, X., Randolph, M. F., Gourvenec, S. \& Wallerand, R. (2014b). Design approach for rectangular mudmats under fully threedimensional loading. Géotechnique 64, No. 1, 51-63, http:// dx.doi.org/10.1680/geot.13.P.051.

Gaudin, C., White, D. J., Boylan, N., Breen, J., Brown, T., De Catania, S. \& Hortin, P. (2009). A wireless high-speed data acquisition system for geotechnical centrifuge model testing. Measmt Sci. Technol. 20, No. 9, 095709, http://dx.doi.org/ 10.1088/0957-0233/20/9/095709.

Gaudin, C., Randolph, M. F., Feng, X., Clukey, EC. \& Dimmock, P. (2012). Centrifuge modelling of a hybrid foundation for subsea equipment. In Proceedings of the 7th international conference on offshore site investigation and geotechnics, London (ed. P. Allan), pp. 411-420. London, UK: Society for Underwater Technology.

Gourvenec, S. \& Randolph, M. F. (2003). Effect of strength nonhomogeneity on the shape of failure envelopes for combined loading of strip and circular foundations on clay. Géotechnique 53, No. 6, 575-586, http://dx.doi.org/10.1680/geot.2003.53.6.575.

Gourvenec, S. \& Randolph, M. F. (2010). Consolidation beneath circular skirted foundations. Int. J. Geomech. 10, No. 1, 22-29, http://dx.doi.org/10.1061/(ASCE)1532-3641(2010)10:1(22).

Gourvenec, S., Vulpe, C. \& Murthy, T. (2014). A method for predicting the consolidated undrained bearing capacity of shallow foundation. Géotechnique 64, No. 3, 215-225, http:// dx.doi.org/10.1680/geot.13.P.101. 
Green, A. P. (1954). The plastic yielding of metal junctions due to combined shear and pressure. J. Mech. Phys. Solids 2, No. 3, $197-211$.

Hodder, M. S., White, D. J. \& Cassidy, M. J. (2013). An effective stress framework for the variation in penetration resistance due to episodes of remoulding and reconsolidation. Géotechnique 63, No. 1, 30-43, http://dx.doi.org/10.1680/geot.9.P.145.

House, A., Olivera, J. R. M. S. \& Randolph, M. F. (2001). Evaluating the coefficient of consolidation using penetration tests. Int. J. Phys. Modelling in Geotechnics 1, No. 3, 17-25.

Mahmoodzadeh, H., Randolph, M. F. \& Wang, D. (2014). Numerical simulation of piezocone dissipation test in clays. Géotechnique 64, No. 8, 657-666, http://dx.doi.org/10.1680/geot.14. P.011, and corrigenda Géotechnique 64, No. 8, 680, http:// dx.doi.org/10.1680/geot.2014.64.8.680 and Géotechnique 64, No. 10, 848-850, http://dx.doi.org/10.1680/geot.2014.64.10.848.

Mana, D. S. K., Gourvenec, S., Randolph, M. F. \& Hossain, M. S. (2012). Failure mechanisms of skirted foundations in uplift and compression. Int. J. Phys. Modelling in Geotechnics 12, No. 2, 47-62, http://dx.doi.org/10.1680/ijpmg.11.00007.

Mandel, J. (1950). Étude mathématique de la consolidation des sols. Actes du colloque international de méchanique, Poitiers (ed. P. Vernotte), vol. 4, pp. 9-19. Paris, France: Ministère de 1'Air (in French).

Mayne, P. W. (2001). Stress-strain-strength-flow parameters from enhanced in-situ tests. In Proceedings of the international conference on in-situ measurement of soil properties and case histories, In-situ 2001, Bali (eds P. Rahardjo and T. Lunne), pp. 27-47. Bandung, Indonesia: Parahyangan Catholic University.

Randolph, M. F. (2004). Characterisation of soft sediments for offshore applications, keynote lecture. In Proceedings of the 2nd international conference on site characterisation, Porto (eds A. Viana de Fonseca and P. W. Mayne), pp. 209-231. Rotterdam, the Netherlands: Balkema.

Randolph, M. F. \& Hope, S. (2004). Effect of cone velocity on cone resistance and excess pore pressures. In Proceedings of the international symposium on engineering practice and performance of soft deposits, Osaka, Japan, pp. 147-152. Tokyo, Japan: Japanese Geotechnical Society.

Randolph, M. F., Jewell, R. J., Stone, K. J. \& Brown, T. A. (1991). Establishing a new centrifuge facility. In Proceedings of the international conference on centrifuge modelling, Centrifuge
'91, Boulder (eds H.-Y. Ko and F. G. McLean), pp. 3-9. Rotterdam, the Netherlands: Balkema.

Randolph, M. F., Low, H. E. \& Zhou, H. (2007). In situ testing for design of pipeline and anchoring systems. In Proceedings of the 6th international conference on offshore site investigation and geotechnics, London, pp. 251-262. London, UK: Society for Underwater Technology.

Randolph, M. F., Yan, Y. \& White, D. J. (2012). Modelling the axial soil resistance on deep-water pipelines. Géotechnique $\mathbf{6 2}$, No. 9, 837-846, http://dx.doi.org/10.1680/geot.12.OG.010.

Stewart, D. P. (1992). Lateral loading of piled bridge abutments due to embankment construction. $\mathrm{PhD}$ thesis, The University of Western Australia, Perth, Australia.

Stewart, D. P. \& Randolph, M. F. (1991). A new site investigation tool for the centrifuge. In Proceedings of international conference on centrifuge modelling, Centrifuge '91, Boulder (eds H.-Y. Ko and F. G. McLean), pp. 531-538. Rotterdam, the Netherlands: Balkema.

Stewart, D. P. \& Randolph, M. F. (1994). T-bar penetration testing in soft clay. J. Geotech. Geoenviron. Engng 120, No. 12, 2230-2235, http://dx.doi.org/10.1061/(ASCE)0733-9410(1994)120:12(2230).

Sully, J. P., Robertson, P. K., Campanella, R. G. \& Woeller, D. J. (1999). An approach to evaluation of field CPTU dissipation data in overconsolidated fine-grained soils. Can. Geotech. J. 36, No. 2, 369-381, http://dx.doi.org/10.1139/t00-072.

Teh, C. I. \& Houlsby, G. T. (1991). Analytical study of the cone penetration test in clay. Géotechnique 41, No. 1, 17-34, http:// dx.doi.org/10.1680/geot.1991.41.1.17.

White, D. J. \& Hodder, M. (2010). A simple model for the effect on soil strength of episodes of remoulding and reconsolidation. Can. Geotech. J. 47, No. 7, 821-826, http://dx.doi.org/10.1139/ T09-137.

White, D. J., Campbell, M. E., Boylan, N. P. \& Bransby, M. F. (2012). A new framework for axial pipe-soil interaction illustrated by shear box tests on carbonate soils. In Proceedings of the 7th international conference on offshore site investigation and geotechnics, London (ed. P. Allan), pp. 379-387. London, UK: Society for Underwater Technology.

Yan, Y., White, D. J. \& Randolph, M. F. (2014). Cyclic consolidation and axial friction for seabed pipelines. Géotechnique Lett. 4, July-September, 165-169, http://dx.doi.org/10.1680/ geolett.14.00032. 